\title{
EL "AFFAIIRE" DREYFUS": UN CASO DE XENOFOBIA Y ANTISEMITISMO EN LOS ALBORES DEL SIGLO XX. IMPLICACIONES POLÍTICAS Y LITERARIAS EN LA PRENSA FRANCESA
}

\section{$M^{a}$ de Gracia Caballos Bejano \\ Universidad de Sevilla}

\begin{abstract}
"L'affaire Dreyfus", an affair about xenophobia and antisemitism at the begining of $20^{\text {th }}$ century. In this essay, when it's the firts centenary of Zola's death, I try to explain its significance on the press in France and nearly all Europe and America, the importance of Zola's intervention detending the jewish captain, and the physical and psychical consequences caused to Zola because of his exile to England.
\end{abstract}

El caso Dreyfus fue una de las grandes crisis políticas y económicas que jalonan el desarrollo de la III República², 1870-1940, y un escándalo judicial, social y político, entremezclado con restos de antiguos conflictos sociales e ideológicos, de base eminentemente racista ${ }^{3}$, que enturbió y dividió la opinión francesa entre el 22 de diciembre

\footnotetext{
${ }^{1}$ Para profundizar sobre cualquier tema bibliográfico relativo al caso Dreyfus consultar, LIPSCHUTZ, Léon: "Bibliographie thématique et analytique de l'affaire Dreyfus", une bibliothèque dreyfusienne, in Cahiers Naturalistes, $\mathrm{n}^{\circ} 35$, Fasquelle, París, 1968, págs. 83-115; n 36, 1968, págs. 189-211; $\mathrm{n}^{\circ}$ 37, 1969, págs. 91-101; n 38,1969 , págs. 191-215.; vol. 3, 1957, págs. 361-356.

GUIEU, Jean-Max: Bibliographie générale informatisée de l'Affaire Dreyfus: son époque et ses répercussions, Société littéraire des Amis d'’Émile Zola et Centre d'Études sur Zola et le Naturalisme, París 2000/ CD-ROM Graphix Communications, San Diego, California.

Consultar igualmente DUCLERT, Vincent(édi.): "J’Accuse...!" \& "Les Preuves" Jean Jaurès cahiers trimestriels, $\mathrm{n}^{\circ}$ 151, janvier-mars, 1999; GUIEU, Jean-Max(édi.): Intolérance et Indignation: L'Affaire Dreyfus, Éditions Fischbaucher, 2000; MAYER, J-M.: “Affaire Dreyfus”, in AMBRIÈRE, M.(dir.), Dictionnaire du XIX siècle européen, PUF, París, 1998, pp. 344-345.

${ }^{2}$ El resurgimiento de los sentimientos racistas se ve motivado en este periodo por diferentes hechos: el desastre de 1870-1871, con la capitulación de Sédan ante los prusianos, el apresamiento de Napoleón III y la desaparición del II Imperio; la depresión económica de los años 80, motivada entre otras causas por la bancarrota de la Union générale, la banca católica; el escándalo financiero de la construcción del canal de Panamá y la bancarrota financiera que llevó a la condena de Ferdinand de Lesseps, de su hijo y del ingeniero Gustave Eiffel, así como al suicidio del financiero barón Jacques de Reinach; y los problemas provocados por los atentados anarquistas de 1892. El francés de fines de siglo considera al judío como la encarnación del mal y como base de las crisis, los escándalos y las derrotas que sacuden a su sociedad.
}

${ }^{3}$ La caracterización del caso Dreyfus como un asunto de racismo ha sido incluso admitida por el actual presidente de la República francesa, Jacques Chirac. Con motivo del centenario de J'Accuse, Chirac dirige una carta a los descendientes de Alfred Dreyfus y de Émile Zola el 8 de enero de 1998. En ella, entre otras cosas, indica la importancia negativa que tomó el caso para Dreyfus, sólo por el hecho der ser judío, y la relevancia que aportó a la 
de 1894, fecha en la que un tribunal militar condena al capitán Dreyfus, y el 5 de enero de 1895, momento en el que es condenado a cadena perpetua por unanimidad, a la degradación militar y a la deportación a la Isla del Diablo"., en la Guayana francesa, acto público llevado a cabo dos días después. Todo este caso sucede entre el 20 de septiembre de 1894, y el 12 de julio de 1906, fecha en la que el capitán Dreyfus fue declarado inocente y se decretó su rehabilitación ${ }^{5}$.

Aunque podríamos creer que este caso puede ser considerado sólo como uno más de la lucha que existe contra aquellos que atacan al estamento militar y a la seguridad del Estado, lo cierto es que es una de las consecuencias que se derivan de los fenónemos de xenofobia ${ }^{6}$

defensa del acusado la participación de Émile Zola: "Malgré la tenacité de la famille Dreyfus, l'affaire aurait pu être classée... Mais un homme s'est élevé contre le mensonge, la bassesse et la lâcheté. Indigné devant l'injustice qui frappait le capitaine Dreyfus, dont le seul crime était d'être juif, Émile Zola lança comme un cri son fameux "J'Accuse"(www.cahiers-naturalistes.com/ chirac.htm)

${ }^{4}$ Las islas del Diablo o Islas de la Salud, como se les llamó posteriormente, son un conjunto de tres islas utilizadas sólo como presidio para los deportados políticos franceses. Entre 1792, momento en el que comenzaron a llegar presos políticos, y 1953, fecha en la que abandonó la isla el último confinado, aunque ya en 1938 fue abolida oficialmente como colonia penal, miles de prisioneros ocuparon sus celdas. Casi ninguno regresaba, ya que o morían de inanición y cansancio o eran consumidos por la malaria y la fiebre amarilla. Sólo en 1852 se contabilizaban en las islas 1.000 presos y entre 1852 y 1856 , hubo allí 8.000 prisioneros, de los que casi 4.000 murieron en ese período. Algunos de ellos, como Clausiot, para mejorar sus condiciones carcelarias, ayudaban en las ejecuciones en la guillotina de sus compañeros más rebeldes.

Uno de los internos, Belvenoi, contribuyó a aclarar la situación interna de los prisioneros, así como sus condiciones de vida y subsistencia, ya que se fugó en 1934, a la tercera tentativa, cruzando la selva y los pantanos cargado con trece kilos de diarios y manuscritos en los que relataba la crueldad del presidio y la ruindad de los guardas. Denis Le Her Seznec ha reclamado en el libro Nosotros los Seznec la exculpación de su abuelo, Guillaume Seznec, condenado en 1923 por un crimen del que, según él, nunca hubo pruebas, ni testigos, ni arma homicida, ni siquiera un cadáver.

Dreyfus es otro símbolo de los errores judiciales, se convirtió en el único inquilino de la menor de las tres islas que forman Las Diablo, que alojaban sólo a prisioneros. Las condiciones infrahumanas de los encarcelados de las Islas del Diablo son hoy mundialmente conocidas por el libro del expresidiario Henri Charrière que intentó evadirse en ocho ocasiones y finalmente lo consiguió en 1952, obteniendo la nacionalidad venezolana, y por la película de Franklin Schaffner, Papillón, en la que Steve Mc Queen y Dustin Hoffman encarnan la lucha desesperada de los reclusos contra un confinamiento que aniquilaba a los prisioneros.

Sobre este presidio y sus presidiarios más conocidos, confrontar el documental del escritor Jaime Hellman, producido por Discovery Chanel y emitido el sábado 8 de septiembre de 2001, a la 1.30 horas, por el emisor Supercable. En él aparece la única imagen cinematográfica de Émile Zola, defendiendo al capitán Dreyfus en su artículo J'accuse. Para obtener mayor información sobre el tema consultar: www. lahora.com.ec/noviembre 20/19 páginas/mundo $4 . \mathrm{htm}$.

${ }^{5}$ Este caso de xenofobía había agriado la vida social francesa. René Dumesnil cuenta cómo sufrió en su juventud al ver a Francia amenazada por los antagonismos que surgían entre padres e hijos o entre hermanos. El no comprendía: "la fureur des jeunes indignés de voir leur pays humilié par l'étranger, le ressentiment de ceux qui voyaient la vérité et la justice bafouées par un public aveugle, .. l'impasse psychologique et morale aussi bien que sociale et politique dans laquelle le pays semblait se laisser perdre" ( BURNS, Colin: "Trois témoins de l'Affaire Dreyfus: Jacques Émile-Zola, Violette Vizetelly, René Dumesnil”, in Cahiers Naturalistes, Grasset, París, $\mathrm{n}^{\circ} 75$, 2001, págs. 377-378). Sin embargo, a pesar de su reprobación personal y de su hastío ante la barbarie antisemita, no pudo hacer evidente su defensa de Zola y su rechazo a la xenofobía y al antisemitismo hasta cincuenta años después, por las hostilidades que podría acarrearle esta denuncia en ese momento.

${ }^{6}$ Confrontar a este respecto ROYU HERNÁNDEZ, Simón: Orígenes de la xenofbia en Europa. El affaire Dreyfus, Madrid., www.lacaverna-de-platón.com/artículosbis/dreyfus.htm. 
y de antisemitismo ${ }^{7}$ que se desarrollan en Francia en este periodo finisecular y que provocan, particularmente en el terreno político y social, una recomposición del entramado de fuerzas en torno a la línea clásica derecha-izquierda ${ }^{8}$. Entre las fuerzas que se consideran de derechas se integran fundamentalmente los nacionalistas, el ejército, los católicos y los antisemitas que se consideran antidreyfus ${ }^{9}$, y en la denominada izquierda, a excepción de los socialistas y de los anarquistas que ven en los judíos una representación del gran capital dominador y opresor que les hace oponerse a ellos, la mayoría de las fuerzas que la integran, incluidos los intelectuales y los anticlericales, se consideran partidarios de la defensa de Dreyfus ${ }^{10}$.

\footnotetext{
${ }^{7}$ David Solar, director de Historia 16, cree que "Dreyfus fue víctima de una situación política de gran antisemitismo. La mayoría de quienes le juzgaron no le consideraban culpable, o tenían las suficientes dudas como para no haberle condenado. Le condenaron por ser judío. La oleada que provocó el caso Dreyfus fue enorme. La intelectualidad más liberal estuvo a su lado, y la conservadora en su contra". Este periodista e historiador piensa que lo más interesante fue la presencia en París en aquellos años del periodista húngaro Theodore Herzl que en su libro El Estado judío, escrito como consecuencia del caso Dreyfus, constata que los judíos no eran totalmente bien acogidos en ningún lugar, y que fueron estas teorías aquí expuestas las que motivaron la creación de un Estado israelí. Confrontar: www.el-mundo.es/1998/01/13/cultural.html.
}

${ }^{8}$ Jules François Camille Ferry(1822-1893), abogado, político, hombre de Estado, presidente del Consejo, 18801881 y 1883-1885, y redactor del periódico Le Temps, en el que denuncia los abusos y las corrupciones del régimen imperial. Este republicano, positivista, anticlerical y profundamente nacionlista evoca, en sus declaraciones colonialistas, la diferencia existente entre las razas superiores y las consideradas inferiores.

${ }^{9}$ Los términos dreyfusistas y antidreyfus o antidreyfusistas son el testimonio de la animadversión y del sentimiento xenófobo que existe en Francia en este periodo finisecular y que se plasman en la figura y en la condena de este capitán judío.

${ }^{10}$ Para buscar las claves de este antisemitismo en Francia, podemos centrarnos en dos referencias:

$1^{\circ}$.- Los judíos son ciudadanos franceses con todos los derechos y deberes que ello conlleva desde

1791.

$2^{\circ}$.- A partir de 1870 , muchos judíos entran en Francia desde el Este, casi todos son comerciantes y no tienen ninguna unión con la tierra, frente al sentimiento francés.

Es esta separación de la tierra y la casi completa dominación del terreno económico lo que fuerza a la enemistad entre franceses y judíos. Por ello quizás Léon Daudet, en enero de 1895, fecha de la degradación de Dreyfus, proclama: "Le misérable n'était pas français", y La Libre Parole el cinco de enero del mismo año publica: "Nous avons pourtant une consolation. C'est que ce n'est pas un vrai Français qui a commis le crime".

Aunque el caso Dreyfus es una expresión clara del antisemitismo existente en la sociedad francesa en la última década del siglo XIX, no es éste el primer caso de racismo conocido ya que, desde antes del comienzo de la II República, el diplomático francés Joseph Arthur Gobineau(1816-1882), en su Essai sur l'inégalité des races humaines, 1853-55, intenta probar de una manera científica y realista la superioridad de la raza nórdica germánica y cómo la mezcla de razas conduce de manera indefectible hacia una decadencia irreversible del hombre y de la sociedad.

Sus doctrinas, que serán el germen de los postulados racistas en Alemania y que alcanzarán su zenit con el régimen nazi, fueron continuadas en Francia por Alphonse de Toussenel(1803-1885), en su Les Juifs, rois de l'époque, 1886, publicada por Marpon y Flamarion en dos volúmenes, y por el discípulo de éste, Edouard Drumont, creador de la Librairie Antisémite, que se convertirá en un especialista del tema con La France juive, essai d'histoire contemporaine, 1886, publicada por Savine, y Les Juifs contre la France, 1899, donde intenta demostrar el complot judío para lograr dominar el mundo, el Protocolo de los Sabios de Sión.

Confrontar a este respecto ROYU HERNÁNDEZ, Simón: Orígenes de la xenofpbia en Europa. El affaire Dreyfus, op. cit. 
Alfred Dreyfus era un oficial francés (Mulhouse ${ }^{11}$ 1855-París 1955), descendiente de una antigua familia de industriales alsacianos de origen judío. Entra a formar parte del ejército francés y del Estado Mayor General con el grado de capitán y está adscrito al ministerio de la Guerra. En poco tiempo, con la ay ${ }^{\circ}$ uda de la prensa que hace de él un monstruo sin ningún precedente en la historia, pasará a ser la víctima propiciatoria de los prejuicios raciales y sociales de sus colegas e involuntariamente va a convertirse en el centro del "affaire".

Entre el 20 y el 25 de septiembre de 1894, el servicio de información francés ${ }^{12}$ descubre, en la papelera del agregado militar alemán en París, el mayor Maximiliam von Schwartzkoppen, informes militares que anuncian, por parte de un oficial francés interino, la oferta de entrega de documentos secretos sobre defensa nacional, sobre movimientos y disposiciones estratégicas del ejército francés y sobre el nuevo armamento contenido en el Manual de tiro de campaña, que estaba aún en proyecto ${ }^{13}$. El documento, sin fecha ni firma,

${ }^{11}$ Las tierras en las que pasa su infancia Dreyfus hacen frontera con Alemania, su mismo apellido es de origen alemán y es de todos sabido la hostilidad que los franceses tienen por los alemanes a causa de las muchas humillaciones militares que les han infringido.

${ }^{12}$ La persona encargada de vigilar los despachos de la embajada alemana en París por parte del Servicio de Estadística francés es Madame Bastian, que realiza el seguimiento desde 1889 hasta 1897, trabajando como mujer de la limpieza.

Esta agente encuentra primero, en la papelera del agregado militar Schwarzkoppen, el borrador de una carta que éste dirige al agregado italiano Panizzardi, indicándole que un cretino traidor, cuyo nombre clave es Jacques Dubois, y al que el agregado alemán denomina irónicamente "el sinvengüenza D", le ofrece secretos militares franceses. Posteriormente, en septiembre de 1894, encuentra otro segundo borrador en el que ya se detallan los secretos que se van a revelar. El general Mercier ordena que se detenga al traidor y el teniente Abboville sugiere que esta traición debe ser atribuida con toda seguridad a algún oficial interino adjunto al servicio, sugiriendo el nombre de Dreyfus. El comandante Henry y el coronel Sandherr falsifican las pruebas para inculpar al oficial judío.

Esta misma espía, en marzo de 1896, encuentra otro borrador del agregado alemán a Esterhazy en el que hablan de la venta de los documentos. Esta carta es la que sirve para inculpar definitivamente a este oficial.

${ }^{13}$ Este documento facilitaba exactamente los planos del freno hidroneumático del obús de $120 \mathrm{~mm}$. y diferentes informaciones importantes relativas a la organización del ejército francés y a la movilización de las tropas que iban a cubrir la frontera del Este. La transcripción del borrador original es la siguiente:

"Sans nouvelles m'indiquant que vous désirez me voir, je vous adresse cependant, monsieur, quelques renseignements intéressants:

$1^{\circ}$ Une note sur le frein hydraulique du 120 et la matière dont s'est conduite cette pièce.

$2^{\circ}$ Une note sur les troupes de couverture(Quelques modifications seront apportées par le

nouveau plan);

$3^{\circ}$ Une note sur une modification aux formations de l'artillerie;

$4^{\circ}$ Une note relative à Madagascar;

$5^{\circ}$ Le projet de Manuel de tir de l'artillerie de campagne(14 mars 1894);

Ce dernier document est extrêmement difficile à se procurer et je ne puis l'avoir à ma disposition que très peu de jours. Le ministère de la guerre en a envoyé un nombre fixe dans le corps, et ces corps en sont responsables. Chaque officier détenteur doit remettre le sien après les manoeuvres.

Si donc vous voulez y prendre ce qui vous intéresse et le tenir à ma disposition après, je le reprendrai. À moins que vous ne vouliez que je le fasse copier in extenso et ne vous en adresse la copie.

Je vais partir en manoeuvres". Citado en http//www.gallica.bnf.fr, Revision du procès Dreyfus devant le Conseil de Guerre de Rennes, pag 21.

Aunque no se puede establecer de manera clara una diferencia entre la escritura de Dreyfus y la del documento, un estudio somero del texto podría mostrarnos su falsa atribución ya que el capitán no participó en ninguna de las maniobras que el ejército francés realizó en 1894. 
es recibido, el 26 de septiembre, por el comandante Hubert Joseph Henry ${ }^{14}$ en el Servicio de información de contraespionaje. Éste lo envía a su jefe, el coronel Jean-Conrad Sandherr ${ }^{15}$, adjunto al jefe del Estado Mayor, y éste al ministro de la Guerra, el general Mercier ${ }^{16}$, que lo remite al presidente de la República, Casimir Périer ${ }^{17}$, y al presidente del Consejo, Charles Dupuy ${ }^{18}$. Se ordena inmediatamente la apertura de una investigación. El jefe del Estado Mayor del ejército, el general de Boisdeffre. ${ }^{19}$, convoca al capitán Dreyfus en el Ministerio de la Guerra con la siguiente orden: "Paris, le 13 octobre 1894. Le général de division, chef d'État Major général de l'Armée passera l'inspection de MM. Les officiers stagiaires dans la journée du lundi 15 octobre courant. M. le capitaine Dreyfus, actuellement au 39e. Régiment d'Infanterie à Paris, est invité à se présenter à cette date et à 9 heures du matin au cabinet de M. le chef d'État Major général de l'Armée, tenue bourgeoise" $" 20$.

Lo recibe el comandante Picquar ${ }^{21}$ que acompaña a Dreyfus hasta el comandante $\mathrm{Du}$ Paty de $\mathrm{Clam}^{22}$. Éste le acusa de alta traición por la entrega del documento al enemigo, ya

\footnotetext{
${ }^{14}$ Hubert Joseph Henry(1846-1898) es un oficial del servicio de contraespionaje del ejército francés. Convencido de la culpabilidad de Dreyfus, es el autor de la carta falsa por la que el capitán fue condenado y por la que él mismo se suicida al ser descubierto.

Es autor también, junto al coronel Sandherr, de la elaboración de otras pruebas falsas para inculpar definitivamente al capitán judío y, junto a du Paty de Clam, cuando Esterhazy es sospechoso de traición, de elaborar otras pruebas para exculparlo y acusar de nuevo a Dreyfus.
}

${ }^{15}$ Este coronel, a la cabeza de la inteligencia militar francesa, es el que ordena al comandante Henry que escriba la carta falsa que le servirá para inculpar a Dreyfus.

${ }^{16}$ Auguste Mercier(1833-1920), general y político nacionalista. Fue ministro de la Guerra desde 1893 a 1895. Cooperó para que se produjese el encarcelarmiento por traición del capitán Dreyfus e impulsó su condena presentando ante el tribunal militar las actas de las que ni el procesado ni el defensor tenían conocimiento y que después no se hicieron públicas. En 1899, facilitó también que la segunda condenà de Dreyfus se produjese en Rennes.

${ }^{17}$ Louis Casimir Périer(1847-1907), militar, político conservador y hombre de Estado. Diputado desde 1881, destaca por su amplia actividad parlamentaria y por los altos cargos que desempeñó hasta convertirse en presidente de la República. Participó como testigo en la revisión del proceso Dreyfus.

${ }^{18}$ Charles Dupuy(1851-1923), político con una actitud represiva contra las reivindicaciones obreras y sindicales que le hacen perder popularidad. Como presidente del Consejo se quedó en minoría a causa de los incidentes en Auteuil y Longchamp, el 12 de junio de 1899, llevados a cabo por los nacionalistas y los antidreyfusistas.

${ }^{19}$ Raoul François Charles le Mouton de Boisdeffre(1839-1905), militar y hombre de Estado. Como jefe del Estado Mayor se opuso en 1897 a la revisión del proceso de Dreyfus, contribuyendo a la absolución de Estherzázy y prestando su confianza al comandante Henry. Al descubrirse en 1898 la falsificacción de Henry, tuvo que presentar su dimisión.

${ }^{20}$ Para leer el documento confrontar http://www.sdv.fr/judaisme/perso/dreyfus/affaire.htm, p. 2.

${ }^{21}$ Georges Picquart(1854-1914), militar francés, nombrado en 1895 jefe del servicio de información del ejército, al percatarse por los documentos a que tuvo acceso y que no aparecieron a lo largo del proceso de la inocencia de Dreyfus y de la trampa que se le había preparado, llegó a enfrentarse a sus jefes por defender al capitán acusado y por testimoniar contra el estamento militar en el proceso contra Zola, por lo que fue encarcelado en la prisión militar de Mont-Valérien y posteriormente deportado a África. Rehabilitado en 1906, fue nombrado general y ministro de la Guerra bajo la jefatura de Clemenceau. 
que su escritura tiene los mismos rasgos que los de la carta que ha aparecido en el despacho del agregado alemán 23 .

La primera información periodística sobre el caso de espionaje relacionado con un oficial extranjero aparece en La Libre Parole que recibe una carta acusadora el 28 de octubre de 1894 y que publica el 29: "Est-il vrai que récemment une arrestation fort importante ait été opérée par ordre de l'autorité militaire?. L'individu arrêté serait accusé d'espionnage. Si la nouvelle est vraie, pourquoi l'autorité militaire garde-t-elle un silence absolu?"24.

El 31 de octubre, L'Eclair informa sobre el arresto de un oficial que no es de alto rango y La Patrie añade que es:"un officier israélite, attaché au Ministère de la Guerre"25

El 1 de noviembre, el periódico republicano de carácter satírico Le Figaro ${ }^{26}$ informa a la opinión pública, por primera vez, del caso Dreyfus, con el título, Une affaire de trahison:

"Des présomptions sérieuses ont motivé l'arrestation provisoire d'un officier français soupçonné d'avoir communiqué à des étrangers quelques documents peu importants. Il faut qu'on sache très vite la vérité".

En su edición nocturna de este mismo día Le Soir adelanta a la opinión pública el nombre del espía: “L'officier en question s'appelle Dreyfus, qu'il avait trente-cinq ans, qu'il était officier d'artillerie et attaché au Ministère de la Guerre"27.

${ }^{22}$ El comandante Armand du Paty de Clam es un oficial apasionado por la grafología a quien se le confía en primer lugar la instrucción preliminar del caso Dreyfus. El arresto del capitán está ya preparado cuando es convocado a ir al Ministerio el 15 de octubre de 1894. Intentan comparar su escritura con la del "bordereau". Para ello, el comandante le pide que escriba una carta por él, ya que tiene una herida en la mano que le impide escribir, utilizando palabras repetidas del documento acusador.

Una vez establecida la acusación y el arresto por alta traición, el comandante le ofrece una pistola pero Dreyfus rehusa suicidarse y es conducido a la prisión de Cherche-Midi donde es sometido a un gran número de pruebas grafológicas, siendo presentadas las conclusiones positivas de du Paty de Clam a tres especialistas: al experto del Banco de Francia, Alfred Gobert, que no está del todo seguro de la similitud de las letras y no considera las pruebas acusadoras; a Pelletier que asegura que las pruebas grafológicas no acusan para nada al capitán; y a Alphose Bertillon, jefe del servicio de Antropometría, que es el único que está seguro de la culpabilidad del oficial y da un informa positivo, al mostrar que Dreyfus ha intentado en la carta imitar la letra de su hermano Mathieu.

El comandante instructor redacta un informe acusador en el que no incluye el informe negativo del primer experto y añade otras pruebas acusadoras que muestra a los jueces militares del proceso y que la defensa desconoce.

Cuando los defensores del caso Dreyfus, por el énfasis puesto por los defensores de Dreyfus y el impulso de la sociedad aumentado por la presión de la prensa, tuvieron acceso a nuevas informaciones negativas para el alto Estado Mayor, el comandante du Paty de Clam fue retirado del servicio activo.

${ }^{23}$ Confrontar: http://www.sdv.fr/judaisme/perso/dreyfus/affaire.htm, p. 3-4.

${ }^{24}$ www.sdv.fr/judaisme/perso/dreyfus/affaire.htm\#.

${ }^{25}$ Ibidem.

${ }^{26}$ Este periódico, fundado en 1828 , como una publicación semanal, estaba marcado en su origen por una clara tendencia satírica. Retomado en 1854 por H. De Villemessant, a partir de 1866 aparece diariamente defendiendo posiciones monárquicas. A lo largo de la III República, sus opiniones giran hacia ideales republicanos aunque de manera moderada, siguiendo en general una línea burguesa. Desde el final de la II Guerra Mundial se convierte en uno de los órganos políticos y literarios de la prensa burguesa. En 1946 aparece Le Figaro littéraire, como publicación semanal. Desde 1978 se publica un Figaro magazine, y desde 1980 un Madame Figaro.

${ }^{27}$ Iconfrontar: www.sdv.fr/judaisme/perso/dreyfus/affaire.htm\#. 
A las 22 horas, la agencia Havas confirma el arresto de un oficial sin facilitar el nombre. Por su parte, el periódico antisemita La Libre Parole titula: "Haute trahison! Arrestation d'un officier juif! Le capitaine Dreyfus!"28. Este periódico en particular, es el que lanza la campaña difamatoria y despierta el ambiente antisemita.

Dreyfus es detenido, se le abre un proceso el 19 de diciembre, se le juzga sobre pruebas que el mismo detenido desconoce. El dosier secreto ha sido elaborado por la Sección de estadística y entregado a los jueces después de las sesiones de deliberación, y, con testimonios contradictorios, es condenado por espionaje y alta traición, el 22 de diciembre del mismo año, por un Consejo de guerra dirigido por el coronel Maurel y formado por 7 oficiales, que lo degradan profesionalmente, el 7 de enero, y lo deportan de por vida a la Isla del Diablo ${ }^{29}$, adonde llega el 13 de abril de 1895. El mismo comandante Henry declara ante el jurado militar y culpabiliza a Dreyfus jurando ante un crucifijo y señalándolo con el dedo: 'Une personne honorable, que je ne puis nommer, m'a averti au mois de mars qu'un officier du Ministère de la Guerre trahissait. Cette même personne honorable m'a précisé, au moins de juif, que cet officier appartenait au Deuxième Bureau... Et ce traître, le voici" ${ }^{30}$. Georges Clemenceau, que luego sería su defensor, en estos primeros momentos del "affaire", ante la evidencia de los falsos testimonios presentados, llega incluso a aconsejar la pena de muerte por considerar al capitán culpable de haber abierto las fronteras de Francia al enemigo. L'Eclair y L'Echo de Paris apoyan maliciosamente la condena e inciden en la culpabilidad en sus artículos.

A partir de este episodio, una fuerte ola de antisemitismo surge en la opinión francesa, fomentada en particular por un cierto número de publicaciones, con una base eminentemente religiosa. En el país de los Derechos del Hombre y del Ciudadano, se intenta crear una especie de hombres inferiores sólo por ser portadores de algún signo característico, la estrella amarilla en este caso, que les impide acceder a los derechos y deberes fundamentales del hombre. La prensa francesa de derecha, en las antípodas del ideal republicano, a través de una serie de publicaciones calumniosas contra los judíos, La Libre Parole ${ }^{31}$, L'Intransigeant ${ }^{32}$, Le Petit Parisien ${ }^{33}$, Le Petit Journal ${ }^{34}$, Psst $^{35}$, se dedica a

\footnotetext{
${ }^{28}$ Ibidem, pág. 3.
}

${ }^{29}$ La Isla del Diablo, es el presidio más duro que tiene Francia en sus colonias. Joseph Reinach acusa al presidente del Consejo, el general Mercier, de ser el culpable de haber encarcelado a Dreyfus, porque en un principio el Consejo de Guerra sólo le condenó a la deportación de por vida: "Les juges militaires n'avaient condamné Dreyfus qu'à la déportation perpetuelle: Mercier, de sa seule autorité, y ajouta la reclusion; et l'Administration pénitentiaire y consentit" (Histoire de l'Affaire Dreyfus, Fasquelle, París, 1901-1911, VII volúmenes, Volumen II, pág. 127).

En 1898, a causa de la revisión de su proceso, se hacen menos duras las condiciones de reclusión en las que el preso estaba, construye un banco con sus manos, para que sirva de ejemplo a los reclusos que pasen por allí y que piensen que han sido injustamente condenados. Papillon, en 1941, recuerda la situación de Dreyfus cuando se sienta sobre el banco, sintiendo las mismas emociones que él: "Ce banc où Dreyfus, condamné innocent, a trouvé le courage de vivre quand même, doit me servir à quelque chose... Dreyfus ne s'est jamais laissé abattre et toujours, jusqu'au bout, il a lutté pour sa réhabilitation. ... C'est vrai qu'il a eu Émile Zola ... pour le défendre ... Il a tenu le coup. Je ne dois pas être moins que lui"(Charrière, Henri: Papillon, Le livre de Poche, París, 1969, pág. 530).

${ }^{30}$ www.agorapolis.com/zola/.

${ }^{31}$ Edouard Drumont(1844-1917), periodista y hombre político, defensor del catolicismo y profundo antisemita, propagador de las tesis racistas de Gobineau. Su labor perodística comienza en el Diable à quatre, periódico 
vituperarlos exaltando los sentimientos antisemitas a través de la figura del capitán Dreyfus, ya que consideran que un judío, aun siendo francés, no puede ser más que un traidor en potencia. Léon Daudet ${ }^{36}$, que se confiesa antidreyfus, dibuja en Le Figaro del 6 de enero, de una manera encarnizada, el delirio de la multitud, mientras le quitaban los galones al traidor, y la imagen descarnada de Dreyfus: " $n$ 'ayant plus d'âge, plus de teint, couleur traître. Sa face est terreuse, aplatie et basse, sans apparence de remords, étrangère à coup sûr, épave de ghetto" "37, así como muestra el sentimiento xenófobo francés y su actitud ante lo alemán, lo judío, lo que viene de fuera: "une seule foi reste fidèle et sincère: celle qui sauvegarde notre race, notre langue, ... et qui nous rend tous solidaires... Le misérable n'était pas Français. Nous l'avions tous compris par son acte, par son allure, par son visage". Esta campaña antisemita se había ya iniciado anteriormente, al levantarse la opinión contra la incorporación de judíos al ejército francés, pues se les consideraba en el fondo como traidores.

dirigido por Villemessant, y colabora en la publicación antirepublicana L'Inflexible, en la que desvela los secretos del director Villemessant, por lo que éste lo expulsa de su periódico. Colaborador del periódico L'Univers, 1833 1914, fundado y editado por Jacques Paul Migne y dirigido por Louis Veuillot de 1848 a 1874, defensor de la Iglesia y de la Santa Sede, ataca posteriormente a los poderes financieros y en particular a los judíos en La France Juive, essai d'histoire contemporaine(1886), que se convierte en el manifiesto antisemita por excelencia. En 1892, funda La Libre Parole, defensor de las tesis socialistas donde desvela los secretos fraudulentos del escándalo de Panamá, girando posteriormente a bases nacionalistas y antisemitas que le convierten en uno de los propagadores del antidreyfusismo. El escritor y periodista georges Darien, fundador del semanario L'Escarmouche, 1883-1894, que protesta contra la bajeza y la traición política y lucha contra el falso espíritu militar, retrata duramente a Drumont en su novela Les Pharisiens, 1891.

${ }^{32}$ Henri Rochefort(1831-1913), periodista y hombre político. Obligado a dejar el periódico Le Figaro en el que colabora, funda en $1868 \mathrm{La}$ Lanterne y en $1869 \mathrm{La}$ Marseillaise. Por tomar posición a favor de la Commune, fue deportado a Nouvelle Calédonie en 1872, de donde se evade, volviendo a París después de la amnistía en 1880 . A partir de su repatriación, orienta su ideario hacia posiciones nacionalistas y funda L'Intransigeant.

${ }^{33}$ Este periódico, fundado en 1876, tiene primero un origen difícil por su marcado carácter radical, pero, comprado en 1880 por Jean Dupuy, director del Siècle, se orienta entonces hacia la información sensacionalista y los grandes reportajes. Posteriormente gira hacia la derecha, publicándose bajo la tutela alemana durante la ocupación. Desaparece en 1944.

${ }^{34}$ Periódico fundado en 1863 por M. Millaud que marca una innovación en la prensa por el gran número de ejemplares ofertados a un bajo precio. Su moral conformista le hace girar hacia una ideología de derecha, convirtiéndose en el portavoz del Partido social francés del coronel de La Rocque, partidario en un primer momento del colaboracionismo de Pétain. Desaparece en 1944.

${ }^{35}$ El periódico Psst, fundado el 5 de febrero de 1898, por los dibujantes Jean-Louis Forain y Caran d'Ache y en el que el dibujo domina sobre la letra impresa, se une también a esta línea crítica y se dedica a desacreditar a los judíos y a los que los defienden. Propaga la idea que todo Semita es un traidor en potencia. En la página 2, del 5 de febrero, acusa a Joseph Reinach de defender a Zola y entregar Francia al enemigo, y en la página 1, del 12 de febrero, acusa al escritor Zola de germanófilo, y de haber asestado con su carta del día 13 de enero, un golpe por la espalda a Francia.

\footnotetext{
${ }^{36}$ Político, escritor y periodista(1867-1942), antisemita, colabora en las campañas de Drumont en La Libre Parole y evoluciona hacia un nacionalismo intransigente fundando en 1907 con Charles Maurras el periódico L'Action française. Fue diputado de 1919 a 1924, siendo condenado y encarcelado por difamación contra el Gobierno, viviendo una experiencia parecida a la de Dreyfus.

${ }^{37}$ JOSPIN, L.: “Allocution officielle au centenaire de J'accuse, Panthéon, 13 janvier 1998”, in Les Cahiers Naturalistes, $\mathrm{n}^{\circ}$ 72, Besançon, 1998, p. 26.
} 
El asunto se olvida en cierta medida hasta 1896, a pesar de los esfuerzos del hermano del condenado, Mathieu Dreyfus, y de la ayuda del primer intelectual antidreyfus, el escritor y periodista judío de extrema izquierda, Bernard Lazare ${ }^{38}$, que intentan probar lo absurdo de la condena y los fundamentos inadecuados sobre los que se había establecido la acusación. Al mismo tiempo, inicia una campaña informativa para atraer intelectuales y políticos y que se sumen a esta defensa, pero no tiene mucho éxito.

El 1 de marzo de 1896, el Servicio de información del Estado Mayor, bajo la dirección del comandante Georges Picquart desde 1895, accede a un documento, una carta-telegrama no enviada por correo ordinario, denominada posteriormente el "petit-bleu", que procede de la embajada alemana, del agregado Schwarzkoppen, y está dirigido al comandante Esterházy. A partir de este momento, el comandante Picquart, persuadido de la inocencia de Dreyfus, lucha por la revisión del proceso y por la acusación del oficial de origen húngaro, el comandante Ferdinand Esterházy, al descubrir por casualidad que su letra es idéntica a la del documento. Pero el teniente coronel Picquart, por su defensa y por querer desvelar la verdad que el Estado Mayor quería ocultar, al que él mismo revela sus sospechas, sufre múltiples ataques sobre su persona y su puesto por parte de sus superiores, en particular del jefe del Estado Mayor del ejército, el general de Boisdeffre ${ }^{39}$ y del comandante Henry, que escribe un artículo en La Libre Parole en el que le acusa de ser el cabecilla de un complot contra Esterházy.

A pesar de los ataques que surgen en la prensa no oficial de derecha sobre la persecución de Picquart $^{40}$, éste es internado el 13 de enero de 1898, el mismo día de la publicación del J'accuse de Zola, en la prisión militar de Mont-Valérien y posteriormente Túnez, no pudiendo por ello llevarse a cabo esta revisión, quedando como consecuencia el proceso paralizado.

El 1 de noviembre, el comandante Joseph Henry, jefe del servicio de contraespionaje, a instancias superiores, redacta un falso documento, fechado el 31 de octubre de 1896, una carta del agregado militar italiano, Panizzardi, al agregado alemán, en la que menciona el nombre de Dreyfus, para agobiar y debilitar al capitán en sus tentativas de defensa ${ }^{41}$.

En su campaña de lucha, y para despertar la conciencia de la opinión social dormida, el hermano del condenado, en septiembre de 1896, extiende la falsa información de que el capitán Dreyfus se ha evadido de la Isla del Diablo, hecho que conmociona a la sociedad francesa; el 5 de noviembre de este mismo año Gabriel Monod afirma en un artículo en Le Temps que Dreyfus ha sido víctima de un error judicial, un día después, el 6, Bernard

\footnotetext{
${ }^{38}$ Es el primer judío que cree en la inocencia de Dreyfus y que se confiesa partidario de su absolución. Es autor entre otras obras de L'antisémitisme, son histoire et ses causes(1894) y de Une erreur judiciaire. La vérité sur l'Affaire Dreyfus, publicada el 6 de noviembre de 1896, en Bruselas, y el 16 de este mismo mes en París, donde explica sus dudas sobre el proceso y la necesidad de una revisión.
}

${ }^{39}$ Tanto Boisdeffre como Gonse instan a Picquart para que persiga a Esterházy, pero le indican que no lo unan al caso Dreyfus.

${ }^{40}$ En La Libre Parole, aparece un artículo contra el militar escrito por Henry, que le acusa de ser el culpable del control urdido contra Esterházy.

${ }^{41}$ El falso documento elaborado por el comandante Henry para corroborar la acusación donde Dreyfus se declara culpable, no debía haber salido de la Sección de Estadística, pero el general Gonse lo recoge y Pellieux lo presenta en el proceso contra Zola, y el ministro Cavaignac lo hace público el 4 de julio de 1898 . 
Lazare publica Une erreur judiciaire. La vérité sur l'affaire Dreyfus ${ }^{42}$, y pocos días después, el 10 de noviembre, aparece publicada en Le Matin, el fac-simil de la carta acusadora, hecho que inquieta en un principio al comandante Esterházy pero que, por el poco eco que alcanza, no tiene apenas trascendencia ${ }^{43}$.

El vicepresidente del Senado y director del periódico La République Française(18791884), el liberal Auguste Scheurer-Kestner, informado por el abogado Leblois y persuadido también de la falsedad del juicio llevado a cabo contra Dreyfus, proclama la inocencia del condenado en una carta abierta a un amigo, Arthur Ranc, publicada el 16 de noviembre en Le Temps, y se entrevista con el presidente Félix Faure ${ }^{44}$ que no escucha las justificaciones del senador y no consigue tampoco que se ordene la revisión del proceso, siendo considerado por la prensa como un agente del sindicato judío ${ }^{45}$.

Por casualidad, a principios de noviembre de 1897, el banquero M. de Castro, reconoce en el original de la carta publicada en el periódico Le Matin, la letra de uno de sus clientes, el comandante Esterházy y se lo comunica a Mathieu Dreyfus y éste, a su vez, al senador Scheurer-Kestner. El 15 de noviembre de 1897, Mathieu Dreyfus publica en varios periódicos la carta por la que acusa al comandante Ferdinand Esterházy de ser el autor del documento y un traidor, así como la conclusión de los estudios realizados por diferentes expertos y grafólogos de que la escritura de Dreyfus no es igual que la del documento en cuestión, el famoso "bordereau". El ministro de la Guerra, el general Billot ${ }^{46}$, ordena una investigación y Esterházy es juzgado en un Consejo de guerra. El 28 de noviembre de 1897, aparecen publicadas también en Le Figaro unas cartas de Esterházy a la señora de Boulancy, una antigua amante despechada a la que había robado dinero, en las que el comandante mostraba su desprecio por Francia y por su ejército, "carta de Ulhan". Este hecho causa sensación en la prensa francesa, aunque los periódicos nacionalistas defienden que son falsas, pero los ecos del escándalo se acallan pronto porque dos meses después, el 11 de enero de 1898 , el comandante es absuelto por unanimidad ${ }^{47}$, impidiendo esta resolución, de manera definitiva, la solicitada revisión de todo el proceso Dreyfus ${ }^{48}$.

${ }^{42}$ Esta obra fue publicada en 1896, en Bruselas, y posteriormente en 1987 y 1988, en París, por Stock.

${ }^{43}$ En octubre de 1896 y ante las acusaciones vertidas sobre Esterházy, el equipo del Ministerio de la Guerra formado por Gozne, Henry y du Paty se reunen con el comamdante para advertirle de ellas. El 18 de octubre, el comandante recibe una carta anómina, Espérance, en la que se le indica que esté alerta ante los acontecimientos que se avecinan.

${ }^{44}$ Félix Faure(1841-1841-1899), político y hombre de Estado, presidente de la III República hasta su muerte en extrañas circunstancias. Fue muy contestado por el asunto de Fachoda, Sudán, por el que Francia cede sus derechos al Reino Unido sobre el Nilo, y por negarse a la revisión del proceso Dreyfus.

${ }^{45}$ Estas críticas hacen que Scheurer-Kestner no sea reelegido vicepresidente del Senado.

46 Jean-Baptiste Billot(1828-1907), general, político y hombre de Estado, es el reorganizador del ejército francés después de la debacle prusiana, siendo nombrado ministro de la Guerra en 1896, en el gabinete de Méline, interviniendo directamente en las primeras incidencias del caso Dreyfus.

${ }^{47}$ Christian Esterházy, sobrino del comandante, revela en junio de 1898 que su tío había urdido también un complot para anular a Picquart con la ayuda de du Paty de Clan y de Henry.

${ }^{48}$ Según Nelly Wilson, el verdadero culpable de la condena de Dreyfus y la posterior liberación del acusado Esterhazy, es el general Billot. Se le acusa de haber ocultado las pruebas que mostraban la inocencia de Dreyfus, 
Aunque $^{49}$ con un artículo que aparece en Le Figaro, el 16 de mayo de 1896, denominado Pour les Juifs, Zola se pone ya en contra del movimiento antisemita en Francia, anunciando su próximo fracaso y considerándolo: “... sans racines aucunes dans le peuple ${ }^{\text {"50 }}$, la primera vez que Zola tiene acceso directo con el asunto Dreyfus fue en 1896, a través de una reunión con Bernard-Lazare que intenta convencerle de la inocencia de Dreyfus, pero, como no tiene pruebas claras, Zola no se decide a entrar directamente ${ }^{51}$. El 5 de noviembre de 1897, Gabriel Monod afirma en el periódico Le Temps(publicación del día 6), que Dreyfus ha sido víctima de un error judicial.

El 13 de noviembre de este mismo año, en una reunión en casa del senador ScheurerKestner, el comandante Picquart informa de sus descubrimientos sobre la falsa carta y afirma la inocencia de Dreyfus ${ }^{52}$. Zola comienza a introducirse en el caso; Bernard-Lazare le muestra su artículo titulado Comment on condamne un innocent y los documentos que tiene sobre el asunto. Habla con el director de Le Figaro, Fernand de Rodays, convencido también de la inocencia de Dreyfus, y le propone la publicación de unos artículos. Como el mismo Zola nos muestra, vemos cómo al principio se introduce por una especie de seducción, pero que a continuación es la necesidad de desvelar la verdad lo que le mueve a entregarse: "le professionnel, le romancier, était surtout séduit, exalté par un tel drame. Et la pitié, la foi, la passion de la vérité et de la justice, sont venues ensuite"53.

de haber ordenado al Consejo de guerra la absolusión de Esterházy. Consultar Paroles et silences dans “J'accuse"..., Cahiers Naturalistes, Besançon, 1998, págs. 71-72.

49 Émile Zola publica en Fasquelle, en 1901, la recopilación de todos sus artículos publicados sobre el caso Dreyfus. Se titula L'Affaire Dreyfus. La Vérité est en marche.

Además de estos artículos, Maurice Le Blond cita, en una recopilación posterior, cuatro artículos que no se encuentran publicados en la primera edición, aparecidos en el periódico l'Aurore:

22 de enero de 1898, "Réponse à l'Assignation". Lettre à Monsieur lé Ministre de la Guerre.

- 14 de abril, Une nouvelle ignominie. En él, Zola muestra su indignación por el nuevo juicio, después de haber sido ya condenado en París, el 23 de febrero de 1898.

- 20 de julio, firmado por Zola, pero escrito por Clemenceau para justificar su exilio y su incomparecencia al segundo proceso de Versalles, el 23 de mayo de 1898.

- 19 de diciembre de 1899, Lettres au général de Galliffet et à Monsieur Waldeck-Rousseau.

Para conocer el artículo inédito del 29 de julio, confrontar RACINE, Jean: "Un article inédit d'Émile Zola", en Cahiers Natralistes, vol. I, 1955, págs. 142-144.

${ }^{50}$ BECKER, Colette(éd.): “Impressions d'audience”, La Vérité en marche, Garnier-Flammarion, Paris, 1969, pág. 60.

${ }^{51}$ Aunque Zola fue el escritor que tomó el asunto Dreyfus como cruzada particular, hay muchos escritores que publican artículos en periódicos. Así, Octave Mirbeau (1848-1917), antimilitarista, el 20 de septiembre de 1896, escribe en Le Journal, una crónica titulada Wagon!, en la que habla de Dreyfus por ser el responsable de las disputas entre el estamento militar. Pero, a partir de 1897, convencido de su inocencia, lo convierte en sus artículos en el perseguido que tiene que ser absuelto por el bien de la humanidad. Confrontar NIVET, Jean-François: "Octave Mirbeau entre espoirs et cauchemars", en Les Cahiers Naturalistes, nº 61, Fasquelle, París, 1987, págs. 218-227).

${ }^{52}$ Entre el 21 y el 29 de junio de 1897, Picquart da al abogado Leblois todo lo que ha descubiero sobre el caso Dreyfus y que ha motivado su aislamiento primero en Alemania y luego en Túnez. Permite a este abogado que pueda utilizar esta información si alguien ataca sus intereses personales o profesionales

${ }^{53}$ COGNY, Pierre: "La rhétorique de la vérité dans "J'accuse", in Cahiers Naturalistes, n 46, 1973, pág. 131. 
El 25 de noviembre, publica el primer artículo con el título de M. Scheurer-Kestner, donde, sin hablar de Dreyfus, defiende por un lado a su amigo el senador, que es calificado en la prensa como un "boche" ${ }^{54}$, y por otro lado se dirige a los políticos y a los militares, encubriéndose bajo el pronombre "on", a los que advierte e incluso amenaza. El 1 de diciembre, aparece el segundo artículo titulado Le Syndicat, en el que ataca a aquellos que rumorean sobre la existencia de un sindicato judío creado para defender a los judíos y atacar a los cristianos. En él indica que el único sindicato que existe es aquel que lucha por que brille la verdad y por que se realice la justicia: "De ce syndicat, ah! Oui, j'en suis, et j'espère bien que tous les braves gens de France vont en être"

El 5 de diciembre, al día siguiente del comienzo del juicio contra Esterházy, aparece el tercer artículo Procès-verbal ${ }^{56}$, en el que comunica las maquinaciones de la prensa antisemita, evidenciando el papel que los espectadores y los actores tienen del caso. Acaba con su campaña de ataque y acoso de los culpables, y comienza con otra de persuasión, no por ello menos dura, para convencer a las masas del castigo infligido a un inocente: "Voilà des citoyens français, nos égaux et nos frères, que l'imbécile antisémitisme traîne quotidiennement dans la boue. On a prétendu les écraser avec le capitaine Dreyfus, on a tenté de faire du crime de l'un d'eux, le crime de la race entière"57. A causa de estos artículos acusadores, el director de Le Figaro le indica que no puede seguir publicándolos debido a la campaña levantada contra el periódico y por la presión negativa que recibe de sus lectores.

Zola, ya inmerso en la defensa de estos ideales y siguiendo con su táctica persuasiva, decide publicar una serie de folletos informativos en la editorial Fasquelle, el primero de ellos aparece el 14 de diciembre, Lettre à la jeunesse ${ }^{58}$. Es una lección que dirige a los jóvenes nacionalistas que gritan contra Scheurer-Kestner: "Nous allons huer un homme, un vieillard, qui, après une longue vie de travail et de loyauté, s'est imaginé qu'il pouvait impunément soutenir une cause généreuse, vouloir que la lumière se fasse et qu'une erreur soit réparée, pour l'honneur même de la patrie française!" 59 . En la carta comenta la función revolucionaria y contestataria que los jóvenes han desempeñado a lo largo de la Historia, su defensa de la humanidad y de la justicia, y les muestra, dejando de lado "l'imbécile

\footnotetext{
${ }^{54}$ Denominación popular y despectiva para caracterizar al ciudadano de origen alemán.

55 BREDIN, Jean-Denis: "Le 13 janvier 1898, il y a un siècle...", in Cahiers Naturalistes, n 72, GrassetFasquelle, Besançon, 1998, pág. 41-42.

${ }^{56}$ Este artículo aparece en el manuscrito original con el título primero de Le Spectacle, pero es tachado y reemplazado por el de Procès-verbal. El texto comienza con: "Ah! Quel spectacle ...", en ROLSEN, Karl: “Quelques textes retrouvés de Zola sur l'affaire Dreyfus”, in Cahiers Naturalistes, n 55, Fasquelle, París, 1981, págs 204).

${ }^{57}$ COGNY, Pierre, op. cit. pág. 131.

${ }^{58}$ Para consultar el documento: http://ourworld.compuserve.com/homepages/bib-lisieux/lesjeunes-htm, págs. 1-6.

${ }^{59}$ Ibidem, pág. 1.
}

A fines de 1897, comienzan las movilizaciones entre los jóvenes intelectuales y en el medio universitario, en particular el que rodea al mundo literario y científico. Sin embargo las facultades de derecho y medicina se consideran antidreyfus. En sus filas se encuentran: Charles Péguy, los hermanos Proust o Mallarmé. 
antisémitisme", cuál debe ser su papel ante el ultraje consumado a un joven militar sólo por el hecho de no querer revisar unas pruebas que, a todas luces, han sido elaboradas para poder condenarlo.

Zola, a pesar de todo, disculpa las acciones de la juventud porque son los políticos y sus órganos los que han “... pourri jusqu'à la jeunesse de nos écoles, et que voilà celle-ci trompée, égarée, lâchée au travers de nos rues, manifestant, ce qui ne s'était jamais vu encore, contre tout ce qu'il y a de plus fier, de plus brave, de plus divin dans l'âme humaine!"60.

El escritor termina preguntándose hacia dónde va la juventud en este camino de locura y sin razón en el que la han introducido, y ella responde a través de sus palabras: "Nous allons à l'humanité, à la vérité, à la justice!"61.

El 6 de enero de 1898 amplía su mensaje y publica su Lettre à la France ${ }^{62}$, donde se dirige a su país y a su patria, al ver cómo se deja arrastrar por el poder iniquidor de una cierta prensa y de unos políticos que toleran que la mentira no permita aclarar la evidente verdad y preguntándose cómo ha podido dejarse “... affoler sous l'imbécile prétexte que l'on insulte ton armée et que l'on complote de te vendre à l'ennemi, lorsque le désir des plus sages, des plus loyaux de tes enfants, est au contraire que tu restes, aux yeux de l'Europe attentive, la nation d'honneur, la nation d'humanité, de vérité et de justice?... comment ton peuple, France, ton peuple de bon coeur et de bon sens, a-t-il pu en venir à cette férocité de la peur, à ces ténèbres de l'intolérance?"63.

Percibe que la intolerancia y el antisemitismo la han impulsado hacia unas vías de insensatez que van de nuevo a conducir a la nueva Francia republicana, de manera irreversible, hacia el camino de la dictadura: “...tu retournes au passé, à ce passé d'intolérance et de théocratie, que les plus illustres de tes enfants ont combattu, ont cru tuer, en donnant leur intelligence et leur sang... des circonstances ont permis de souffler au peuple la rage antisémite, on l'empoisonne de ce fanatisme, on le lance dans les rues, criant: “A bas les juifs! A mort les juifs!”...La République est envahie par les réactionnaires de tout genre, ils l'adorent d'un brusque et terrible amour, ils l'embrassent pour l'étouffer"64.

Termina Zola mostrando su esperanza en el porvenir de Francia, donde la verdad resurgirá sobre las cenizas de la mentira, gracias a los franceses que, como él, en defensa de la justicia, no tienen miedo a publicar y a expresar todas las iniquidades que se han hecho contra ella: "Et ce sera pour ta gloire finale, France, car je suis sans crainte au fond, je sais qu'on aura beau attenter à ta raison et à ta santé, tu es quand même l'avenir, tu auras toujours des réveils triomphants de vérité et de justice!"

\footnotetext{
${ }^{60}$ Ibidem, pág. 3.

${ }^{61}$ Ibidem, pág. 5.

${ }^{62}$ Para consultar el documento: http://ourworld.compuverse.com/homepages/bib-lisieux/lefranc.htm, págs. 1-6

${ }^{63}$ Ibidem, pág. 1.
}

${ }^{64}$ Ibidem, págs. 3-4. 
Unos días después, el 10 de enero, Bernard-Lazare publica su tercera memoria, titulada Comment on condamne un innocent, donde aparece dos veces el término J'accuse: "J'accuse le commandant Esterházy... J'accuse le colonel du Paty de Clan".

A partir del 13 de enero de 1898, el asunto Dreyfus entra en su etapa revolucionaria, motivada por la absolución del comandante Esterházy, el día 11, considerada por Zola como un crimen social que desvirtúa la imagen de Francia. Este intelectual comprometido, acostumbrado a la injusticia y a la maledicencia, decide, ante este error judicial, defender abiertamente al militar judío, pero no por su ascendencia familiar o militar, sino porque está en contra de la injusticia llevada a cabo contra un hombre y, por extensión, contra todos los hombres ${ }^{65}$. Por ello, para hacer que la verdad y la justicia afloren y que los culpables salgan de su escondite, publica, en el periódico L'Aurore. ${ }^{66}$, una carta abierta al presidente de la República, Félix Faure, a la que su director, Clemenceau, con la autorización de Zola, pone el título de "J'accuse" ${ }^{\text {"67 }}$, para mostrarle toda la verdad que él ignora sobre el caso y porque "Mon devoir est de parler, je ne veux pas être complice" 68 ; le indica además que, después de una exposición detallada de los cuatro años del caso, va a denunciar a "toute la tourbe malfaisante des vrais coupables" ${ }^{\prime 9}$. En esta carta, con un efecto revulsivo, deja de nuevo la persuasión y vuelve a su política de ataque violento a los culpables y a sus cómplices, en particular al comandante du Paty du Clam y, en general, al Estado Mayor francés. En ella les acusa de haber castigado sin pruebas al capitán Dreyfus, sólo por el hecho de ser judío.

Él mismo declara, a fines de enero, haber estado influenciado por el poder de la justicia y la fuerza disuasoria de los periódicos, ya que, en un primer momento, creía que Dreyfus había sido condenado justamente, pero posteriormente, cuando empieza a publicar sus artículos en Le Figaro, percibe las irregularidades llevadas a cabo para ocultar al verdadero culpable, está seguro de su inocencia y se enfrenta abiertamente a todos por él: “... complètement seul, ayant tout et tous contre nous: le gouvernement, à cause de l'erreur commise; les classes moyennes, aveuglées et incapables de raisonner; le peuple, infecté de la peste de l'antisémitisme". Zola, en una ensoñación puramente mesiánica, llega incluso a comparar la condena del judío Dreyfus con la del judío Jesús nazareno, mediante un texto de Renan: “ Le pouvoir civil, bien qu'innocent de la mort de Jésus(il ne fit que

${ }^{65}$ El escritor suizo Édouard Rod evidencia en diferentes artículos sobre el caso Dreyfus que, aunque no está de acuerdo con Zola en la inocencia del capitán, cómo fluye por todas partes el idealismo moral y social del escritor, emanando por las diferentes partes de su producción su lucha por defender con claridad la justicia y la verdad.

${ }^{66}$ El diario L'Aurore, de carácter republicano-socialista, se funda en París en 1897 por E. Vaughan, antiguo redactor y administrador de L'Intransigeant, con la colaboración de Georges Clemenceau y F. De Pressensé. Se convierte en uno de los máximos representantes de la prensa independiente, conocedora de su responsabilidad y fuerza social y sin manipulación económica. Desaparece, como otros muchos diarios en 1914.

En septiembre de 1944, aparece en París, con el mismo nombre, un diario de información general dirigido por Robert Lzzurick, con la colaboración de Jean Piot y Paul Bastid. En julio de 1948, absorbe al periódico France Libre, de R. Peigné.

En julio de 1978, Robert Hersant compra el periódico para Franpresse, convirtiéndose, a partir de 1984, en una edición parisina de Le Figaro.

${ }^{67}$ Para consultar el documento: http://www.france2.fr/evenement/jaccuse1.htm, págs. 1-9.

${ }^{68}$ Ëmile Zola, J'accuse...! Lettre au président de la République, Leerte à M. Félix Faure, in http://pero.magic.fr/tremong/pascal/lois/jaccuse.html, pág. 1,

${ }^{69}$ Ibidem, pág. 1. 
contresigner la sentence, et encore malgré lui), devait en porter lourdement la responsabilité. En présidant à la scène du Calvaire, l'État se porta le coup le plus grave"70

Muestra que es un crimen apoyarse en el patriotismo, en el fanatismo y en el antisemitismo, para hacer que la opinión francesa les apoye ante un complot que lo que quiere es ahogar la verdad y la justicia: "C'est un crime que d'exploiter le patriotisme pour des oeuvres de haine, et c'est un crime, enfin, que de faire du sabre le dieu moderne, lorsque toute la science humaine est au travail pour l'oeuvre prochaine de vérité et de justice" ${ }^{\text {"71 }}$. Termina mostrando que es difícil ocultar la verdad porque, gracias a las personas que la defienden a ultranza, ésta siempre sale a la luz: "quand on enferme la vérité sous terre, elle s'y amasse, elle y prend une force telle d'explosion, que, le jour où elle éclate, elle fait tout sauter avec elle, on verra bien si l'on ne vient pas de préparer, pour plus tard, le plus retentissant des désastres" $" 72$.

Esta carta $^{73}$, en la que aparece la célebre frase: "La vérité est en marche et rien ne l'arrêtera"74, produce en la sociedad, según indica Léon Blum en sus Souvenirs sur l'affaire, 1935, un efecto de tranquilidad ante el poder arrollador de la justicia: "Nous étions là, atterrés, désespérés, quand l'aspect des choses changea soudain, Un poing énergique venait de briser les vitres dans cette chambre verrouillée où la cause de la révision était vouée à l'asphysie" ${ }^{37}$, y, según Anatole France, por este acto, Zola se convierte en el portavoz de la conciencia humana, como indica en la oración fúnebre que le dirige al escritor el 5 de octubre de 1902, fecha de su enterramiento: “... il n'avait pas seulement révélé une erreur judiciaire, il avait dénoncé la conjuration de toutes les forces de violence

${ }^{70}$ RENAN, Ernest: La Vie de Jésus, Gallimard, coll. Folio, París, 1974, chap. XXVII, págs. 414-415. Esta comparación, la cita anterior sobre su entrada en el tema Dreyfus, así como los sentimientos y las ideas sobre el asunto Dreyfus, aparecen referidas en la entrevista que, el 24 de enero de 1898, Zola concede a Robert Sherard, corresponsal en París de diferentes periódicos americanos. La entrevista aparece el 26 de enero, en primera página, en el New York Journal de William Randolph Hearst, con el título Emile Zola speaks throuh the Journal, es considerada como una Lettre au peuple américain. Todo lo que rodea a esta entrevista, el periodista lo evoca en su libro Twenty years in Paris, Hutchinson, London, págs. 471-480.

La traducción de la entrevista enviada a Londres en inglés, es realizada por los servicios de la policía, siendo utilizada en el proceso contra Zola, y conservada en los Archivos Nacionales, en el fondo Félix Faure, 460 AP/18. Está transcrita en el artículo de Alain Pagès "Une interview inédite d’Émile Zola en janvier 1898", in Cahiers Naturalistes, $\mathrm{n}^{\circ} 72,1998$, págs. 180-183.

${ }^{71}$ J'accuse, op. cit. pág. 7.

${ }^{72}$ Ibidem, pág. 7.

${ }^{73}$ Con motivo de la aparición de J'accuse, los periódicos presentan, entre enero y febrero de 1898, diferentes encuestas para contrastar la opinión de los franceses. Destacamos las publicadas por La Critique, $\mathrm{n}^{\circ} 71$ y $72(5$ y 20 de febrero), y L'Essor. Journal littéraire, $\mathrm{n}^{\circ}$ 7(30 de enero). Ver la reproducción en el artículo de Philippe Oriol, “Autour de "J'accuse". Quelques documents inédits", in Cahiers Naturalistes, nº 72, 1998, págs. 173-178.

${ }^{74}$ Ibidem, pág. 7.

${ }^{75}$ JOSPIN, Lionel, op. cit. pág. 27.

Sin embargo, no todos los escritores y críticos veían de buen grado la injerencia política de Zola. Así Ferdinad Brunetière, director de la Revue des Deux Mondes (fundada en 1829 por J. Buloz, con un carácter eminentemente artístico y literario, evoluciona, bajo la dirección de Brunetière, hacia una tendencia católica y más conservadora), acusa al escritor por esta injerencia: "L'intervention d'un romancier, même fameux, dans une question de justice militaire, m'a paru aussi dáplacée que le serait, dans la question des origines du romantisme, l'intervention d'un de gendarmerie". 
et d'oppression unies pour tuer en France la justice sociale, l'idée républicaine et la pensée libre... Les conséquences de son acte sont incalculables... Il en sort un nouvel ordre de choses fondé sur une justice meilleure et sur une connaissance plus profonde des droits de tous" $"$.76.

En esta carta, en la que, como hemos visto, el teniente coronel Du Paty du Clam es considerado como la persona que ha urdido todo el complot y ha convencido a sus jefes, los generales Mercier, Boisdeffre y Gonse ${ }^{77}$, Zola está pidiendo al mismo tiempo un proceso para é $1^{78}$. Un día después, el 14 de enero, en L'Aurore, se publica una primera carta de protesta firmada por un gran número de intelectuales que se unen a la protesta del escritor y solicitan una revisión del proceso Dreyfus ${ }^{79}$; a ella le sigue otra el 16. Pero el presidente Jules Méline ${ }^{80}$ actúa como si el caso Dreyfus no existiese mientras que, por otra parte, Albert de Mun $^{81}$, representante de la derecha nacionalista, y Cavaignac ${ }^{82}$, que representa a los radicales, exigen reparar el ultraje que se ha infligido al Ejército y Méline accede a que el ministro del Ejército, el general Billot, presente una acusación contra Zola.

El proceso tiene lugar entre el 7 y el 23 de febrero de 1898. El juicio tuvo mucha audiencia y un gran número de personajes pasaron por el banquillo, entre otros el teniente coronel Picquart que tuvo el valor de explicar cómo había descubierto la culpabilidad de Esterházy y todo el complot establecido por el Estado Mayor francés para que Dreyfus siguiese en prisión y se acallase el asunto, aunque esta declaración pudiese ser considerada por el Alto Mando negativa para su persona desde un punto vista profesional: "Demain, peut-être, je serai chassé de cette Armée que j'aime et à laquelle j'ai donné vingt-cinq ans de ma vie! Cela ne m'a pas arrêté lorsque j'ai pensé que je devais rechercher la vérité et la

\footnotetext{
${ }^{76}$ Ibidem, pág. 31.
}

77 Sobre el asunto de la responsabilidades, Nelly Wilson y otros críticos no comprenden cómo Zola se ha equivocado tanto al inculpar a los responsables, puesto que el papel directivo del general Mercier está del todo probado.

${ }^{78} \mathrm{Al}$ final de la carta, Zola exclama: "Je n'ai qu'une passion, celle de la lumière, au nom de l'humanité qui a tant souffert et qui a droit au bonheur. Ma protestation enflammée n'est que le cri de mon âme. Qu'on ose donc me traduire en cour d'assises et que l'enquête ait lieu au grand jour!" (J'accuse, op. cit. pág. 8). Zola sabía que con estas acusaciones se autoinculpaba, al ir contra los artículos 30 y 31 de la ley de Prensa de 1881, que penaban los delitos de difamación.

${ }^{79}$ Entre otros intelectuales firman Anatole France, Émile Duclaux, director del Instituto Pasteur, Marcel Proust y Daniel Halévy. Esta caracterización de "intelectales" fue aplicada con un matiz despectivo por la prensa que apoyaba a los opositores de Zola.

${ }^{80}$ Presidente de 1896 a 1898, bajo su gobierno el caso Dreyfus tuvo un nuevo impulso. Al oponerse a la revisión del proceso, tuvo que presentar su dimisión en 1898.

${ }^{81}$ El conde de Mun (1841-1914), de tendencia monárquica y posteriormente republicana, como representante del catolicismo social, intenta establecer, dentro del marco de los sindicatos mixtos, una colaboración entre las diferentes clases sociales por medio de los sindicatos mixtos, patrón-obrero, bajo los auspicios del Estado. Defiende el trabajo de los obreros y el de las mujeres en particular.

${ }^{82}$ Este político y hombre de Estado republicano(1853-1905), de tendencia progresista y antidreyfus, tuvo que dimitir de su ministerio en 1899 a causa de la revisión del proceso Dreyfus. Es miembro de la Ligue de la Patrie française y de la Ligue patriotique des intérêts français, dirigida por Barrès, que defienden intereses antidreyfus. 
Justice. Je l'ai fait, et j'ai cru rendre en cela un plus grand service à mon pays et à l'Armée. C'est ainsi que j'ai cru qu'il fallait faire mon devoir d'honnête homme" ${ }^{83}$.

El 21 de febrero, Zola, con el ardor y la entrega que le caracterizan, declara ante el tribunal: "Dreyfus est innocent, je le jure. J'y engage ma vie, j'y engage mon honneur. A cette heure solennelle, devant ce tribunal qui représente la justice humaine, devant vous, messieurs les jurés, qui êtes l'émanation même de la nation, devant toute la France, devant le monde entier, je jure que Dreyfus est innocent" ${ }^{\prime 84}$.

Por esta carta escandalosa, con una venta de 300.000 ejemplares en pocas horas, el escritor fue condenado por difamación por la Audiencia del Sena a un año de prisión y a una multa de tres mil francos, la más alta de las penas recomendadas por la acusación. A causa de esta sentencia denigrante para unos y justa para otros, se producen múltiples manifestaciones a favor y en contra de Zola, no sólo en Francia sino por toda Europa ${ }^{85}$ e incluso en los

${ }^{83}$ BREDIN, Jean-Denis, op. cit., pág. 47.

Con relación a esta declaración, la prensa analiza el papel positivo y honesto del teniente coronel Picquart, apareciendo artículos sobre él en: Le Figaro, 12 de febrero de 1898, Une conscience. Le lieutenent-colonel Picquart, de Joseph Reinach; L'Aurore, 12 de febrero, L'Affaire Dreyfus. Un héros. Le lieutenet-colonel Picquart, de Francis de Presensé; o el 19 de febrero, L'affaire Zola, de Edmond Frank. Confrontar a este respecto PAGÈS, Alain: Émile Zola, un intellectuel dans l'affaire Dreyfus, Librairie Séguier, Paris, 1991.

${ }^{84}$ Ibidem, pág. 48.

${ }^{85}$ En casi todos los países europeos surgen difrentes artículos a favor y en contra de la condena de Zola y del caso Dreyfus:

- En la prensa austriaca, en particular el semanario Die Wage y el diario Neue Freie Presse(Nueva Prensa Libre), hacen llegar a Zola 16.000 firmas recogidas en las principales ciudades austríacas. La prensa liberal se declara partidaria de la defensa de Dreyfus, criticando el papel del Ejército y de la Iglesia, viendo en ellas la mano de la derecha reaccionaria; mientras que la prensa cristiana piensa que los defensores de Zola y de Dreyfus están pagados por los judíos. Entre estas dos tendencias están la prensa social-demócrata, que piensa que todo el asunto es un problema levantado por la burguesía, pero que la clase obrera apenas está informada.

A Zola le llegan también un gran número de cartas postales con su imagen, la de Dreyfus, la del abogado Lahori y de Esterházy, muchas veces con la cara tachada. Confrontar el artículo de ZIEGER, Karl: "Les réactions autrichiennes à l'affaire Dreyfus(documents)", in Cahiers Naturalistes, nº 62, 1988, págs. 22.

- La prensa española, a pesar de las virulentas tomas de postura en el caso Zola y la casi unánime posición de apoyo por parte de los intelectuales, al ser un estamento en ciernes y aún de escasa consideración social, no tiene una toma de postura inmediata y, los periódicos de mayor tirada, tal vez creyendo reflejar el sentir general de los españoles ante el fallo de un alto tribunal francés, no quieren tomar posturas comprometidas y se deciden por buscar justificaciones históricas: “ ¿Está el honor del Ejército y de la patria por encima de las personas? . El día en que la suspicacia francesa halló en su camino al traidor judío Dreyfus, estalló con violencia nunca vista. Por eso, la prensa de hoy se felicita en general del veredicto [contra Zola], no por pasión de venganza ni de odio, sino por patriotismo y por el honor del Ejército".

Uno de los primeros defensores de Zola es el intelectual Vicente Blasco Ibañez que había proclamado ya antes de la condena, en los primeros días del año 1898, que Zola estaba solo, pero que éste era el destino de los que piensan por su cuenta: "El escritor que no lucha, que no se pone en contradicción con el público, que no choca con él, que no es insultado, es un enano intelectual, un falso talento". En este periodo el escritor valenciano era el director del periódico El Pueblo, donde informa a sus lectores de los hechos acaecidos sobre el caso Dreyfus y sobre la actuación de Zola. Con los millares de lectores que enviaron su adhesión a Zola, Blasco Ibañez elaboró un album y se lo envió a París. El album, denominado À Émile Zola. La Ville de Valence, 1898, tiene, en la página ${ }^{\circ}$ 2, una carta manuscrita del escritor valenciano que es muestra de la evidencia de adhesión y de reconocimiento:

Illustre maître:

La population de Valence, sans distinctions de catégories, la grande dame comme la modeste ouvrière, l'homme d'études comme le plus simple artisan, salue l'éminent écrivain. le premier caractère de notre siècle. 
Nous ne prétendons certes pas nous mêler à l'important problème judiciaire qui se débat aujourd'hui en France; mais nous admirons votre noble et sublime attitude, vous qui descendzs du piédestal des génies en bravant tout: l'impopularité, la calomnie, l'insulte, pour servir la justice et la vérité.

Des géants tels que vous, des caractères comme le vôtre son(sic) absolument indispensables pour la régénération de l'époque actuelle d'erreurs et de corruptions que nous traversons.

Si Paris vous tourne le dos et vous bafoue, sachez bien qu'en Espagne, sur la côté bleue de la Méditérranée, où brille un soleil ardent et où fleurit l'oranger, il y a une ville, dévote de l'art, amante de la liberté et de la justice, qui adore le poète, l'acclame et vénère en lui l'homme juste qui ne craint pas de se sacrifier pour la (sic) vérité.

Valencia (Espagne), 15 de Fébrier 1898. ( ALCORN, Clayton: "L'album de Valence: un grand hommage à Zola”, in Cahiers Naturalistes, n 53 , Fasquelle, París, 1979, págs. 145-147).

Sobre el número de artículos publicados por Blasco Ibañez confrontar VAYSSIÈRE, Jean: "L'Affaire Dreyfus à Valence: Blasco Ibañez", in Cahiers Naturalistes, n 51, Fasquelle, París, 1977, págs. 97-108.

El periodista y dramaturgo Joaquín Dicenta asegura, poco después de la muerte del escritor, que sintió la muerte de Zola más que la de su propia madre. A Eduardo Zamacois, corresponsal de La Tribuna en París, director de la revista barcelonesa Vida galante y fundador de las revistas madrileñas El cuento semanal y Los contemporáneos, le rompieron la nariz en una revuelta y Pío Baroja narra en sus memorias un enfrentamiento en las calles de París entre dreyfusistas y antidreyfusistas en el que coincide con los hermanos Machado. No explica la posición que en la melé (sic) guarda cada uno, aunque en el caso de Antonio parece obvio. Sólo refiere que, cuando lo creía perdido, ve, de pronto, al joven Antonio Machado que cojeaba visiblemente: «...¿Qué le ha pasado a usted?, le dije yo. ¿Le han dado algún golpe?... No, me respondió, es que se me ha perdido el tacón de la bota... Lo buscó al salir, y, cosa rara, lo encontró, y se lo volvió a poner, y lo sujetó dando golpes con el pie en la acera».

Puede decirse que, casi de manera unánime, en la mayor parte de la prensa nacional se producen violentas reacciones contra la decisión de los tribunales franceses de condenar al escritor Zola. Blasco Ibáñez se pregunta cómo Francia "podrá justificar ante la posteridad... haber llevado al más ilustre de sus hijos a la cárcel". Posteriormente, en marzo, escribe en Don Quijote: “¿Cómo podrá esa nación [Francia] justificar ante la posteridad el hecho de haber llevado al más ilustre de sus hijos a la cárcel, rapándole la cabeza, afeitando su barba, vistiéndole el uniforme de los ladrones y los asesinos, sometiéndole a todas las duras pruebas que han de sufrir los delincuentes como castigo por sus crímenes?".

El periódico madrileño El Imparcial, 1867-1933, fundado por Eduardo Gasset y Artime, con una orientación liberal moderada, incluye al día siguiente de la condena, una crónica de su corresponsal en París, Azurbialde, para informar de que, ayer, Zola fue condenado a un año de prisión, 3000 francos de multa y las costas. El periodista cuenta la anécdota que: "Zola, mientras se leía la sentencia, estaba mordiendo un caramelo".

El Heraldo de Madrid, diario madrileño, 1890-1956, hereda el nombre de un periódico moderado dirigido por Luis Sartorius, conde de San Luis, en los primeros años del siglo, 1905, se asocia con El Imparcial y El liberal, fundado en 1879 por Isidoro Fernández Flores, portavoz de los liberales durante la Restauración, y son en buena medida los causantes del derrocamiento de Maura en 1909. Este diario refiere que su defensor, Clemenceau, había pronunciado un vibrante alegato en su defensa, que culmina con la frase lapidaria: "Nosotros comparecemos ante vosotros, jurados de Francia. Vosotros compareceréis ante la historia"; a la salida de la sala, el condenado exclamó: “¡Son unos caníbales!”, mientras la multitud irrumpía en una ruidosa ovación y vivas al Ejército y a Francia. Sin embargo también publica que no quiere discutir la sentencia e ir contra el poder judicial y militar establecido democráticamente en Francia, por ello añade: "Nada más lejos de nuestro ánimo que discutir la sentencia. Carecemos de algunos datos necesarios para formar juicios sobre materia tan delicada".

El Progreso no da crédito tampoco a esta condena que convierte a la justicia francesa en irresponsable e inculta: "A la gloria de Zola sólo le faltaba la sentencia de un tribunal condenándolo a la prisión. Lo ha condenado el pueblo francés, el pueblo impío, patriotero, irreflexivo, guiado por el agitador más ruidoso (...) Zola es una gloria de la Francia, y el pueblo francés ha humillado a Zola (...) Ese pueblo imbécil que grita "¡Muera Zola!"; ese pueblo miserable que le silba debía recordar que si es grande, que si su influencia es fecunda en la labor intelectual de Europa, no es por sus ejércitos, no por el brillo de sus armas, no por sus gestas militares, sino por los grandes pensadores que han defendido el espíritu francés a los cuatro vientos; por los Víctor Hugo, los Balzac, los Taine, los Zola".

Además de las sucesivas críticas que aparecen en los periódicos y revistas, casi la totalidad de los intelectuales españoles se pronuncian ante esta sentencia tan polémica. El escritor Enrique Gómez Carrillo que ha vivido muchos años en París, aunque es guatemalteco en realidad, está vinculado a la cultura española, se opone también abiertamente a la sentencia y escribe en la primera semana de marzo en Madrid Cómico: "En nombre de la juventud española, Madrid Cómico protesta contra la sentencia; protesta contra la burguesía francesa y protesta 
también -con verdadera tristeza- contra la juventud de París cuya actitud ha sido repugnante por primera vez en la vida de la gran nación francesa, cuna en otro tiempo de la Libertad y hoy sepulcro de la Tolerancia».

No todo la prensa se muestra en contra de la sentencia y a favor de Zola. Así en España Artística, José de Cuéllar entrevista a Carrillo. Éste además de manifestar su odio a Martínez Ruiz, Azorín, por plagiario, estará en contra del escritor francés por no oponerse a los judíos: "Zola no tiene razón... ¡Los judíos! A los judíos les odia toda Francia. Es mal pleito el de los judíos. ¡Yo también les tengo rencor!... ¡Los judíos! ¡Los judíos!... Aquí, en España, no pueden ustedes comprender eso; pero Francia odia a los judíos... Yo amo París"».

La Lectura Popular, en la línea antidreyfus, en un artículo del primero de abril, ataca también a los judíos y a Zola:: “¿Quién no conoce a Zola? (...) ¿quién no conoce al detractor de la Virgen Santísima, al propagador incansable de la inmoralidad y el escepticismo, al escritor obsceno? ¿Quién no sabe que ese escritor venal se ha puesto de parte de los judíos en el ruidoso proceso del traidor Dreyfus haciendo causa común con todos los mal intencionados de la tierra?".

Es curioso resaltar que en España se produjo también una especie de caso Dreyfus y como Zola, los intelectuales españoles también salieron en defensa de los anarquistas de Montjuïc, en el momento en que dos de los presos, Suñé y Callis, insisten en que fueron martirizados en la prisión y amenazan con publicar su experiencia. Los periódicos exigen una investigación seria sobre las torturas iniciadas y comparan frecuentemente el ambiente creado por el proceso Montjuïc con el producido en el caso Dreyfus.

Los acontecimientos se desencadenaron por el estallido de una bomba, el 7 de junio de 1896, en la calle barcelonesa de Cambis Nous durante la celebración de una procesión del Corpus en la que intervenían los cargos militares y los dignatarios religiosos de la diócesis, presididos por el obispo. Seis personas murieron en el acto y 42 resultaron heridas. Una campaña de la prensa más estricta se levantó contra todo lo que mostrase atisbos de anticlericalismo o de librepensamiento, de modo que el temor se generalizó. Diversos analistas mostraron por su parte su extrañeza ante el hecho de que la bomba no se hubiese dirigido contra la cabeza del cortejo, en la que iban los dirigentes, sino contra su parte trasera, donde formaban las capas más humildes. Se lanzaba en suma la sospecha de que detrás del atentado estuviera en realidad la misma policía, interesada en encontrar un pretexto que le permitiese actuar de manera impune contra personas ideológicamente molestas. Una feroz represión llevó a las cárceles a más de 400 detenidos, casi todos anarquistas, gran parte de los cuales comparecieron como acusados en un proceso plagado de incidentes, criticado por su falta de garantías constitucionales y que acabó con la condena a muerte de cinco implicados. Las repercusiones en el extranjero no se hicieron esperar y en agosto de 1897 el italiano Michele Angiolillo asesinó a Cánovas para vengar a sus compañeros anarquistas. Con el inicio del 98 se impone una necesaria revisión de los acontecimientos.

- La importancia del caso Dreyfus en la prensa inglesa también fue enorme a lo largo de casi todo el proceso. Tanto en The Times, diario independinte y muy influyente en la sociedad inglesa de este periodo; como en The Daily Telegraph, periódico conservador, que dedica números enterios al caso Dreyfus, y en The Manchester Guardian, periódico liberal.

Con motivo de la muerte del escritor naturalista, el periódico The Times, el 30 de septiembre de 1902 publica: "En intervenant dans l'Affaire Dreyfus, Zola agit en sens inverse de ses propres intérêts matériels...Et pourtant il n'a pas fléchi. Il a agi parce qu'il croyait qu'il avait raison d'agir ainsi". (BURNS, Colin A.: "Le retentissement de l'Affaire Dreyfus dans la presse britannique en 1898-1899: esquisse d'un projet de recherches futures", in Cahiers Naturalistes, nº 54, Fasquelle, París, 1980, pág. 257).

- Con respecto a la prensa polaca, estaba completamente interesada en el caso Dreyfus y en la actuación de Zola al respecto. El publicista más conocido Aleksander Swistochowski, redactor del periódico Prawda(La Verdad), publica diferentes artículos referidos al caso Dreyfus, pero no cuestionándose su inocencia o su culpabilidad, que él desconoce por lejanía, sino como prueba de la enfermedad y la debilidad de la sociedad y el estado francés. Igualmente defiende la participación de Zola, no por su posicionamiento, sino por la fuerza y el coraje con que defiende sus opiniones, intentando conquistar la justicia para su causa. Sobre la prensa polaca confrontar KULCZYCKA-SALONI, Janina: "L'Affaire dreyfus vue par les Polonais", in Cahiers Naturalistes, n 54, Fasquelle, París, 1980, pp. 258-265.

- Este problema de antisemitismo, así como el enfrentamiento entre el ejército y la masa social francesa tuvo también su importancia en la prensa rusa aunque resulta en cierto sentido incomprensible para este pueblo. Los periódicos rusos se mostraron en general defensores del ultraje infligido a Dreyfus, con la excepción de dos periódicos antidreyfus Le Nouveau Temps y las Nouvelles de Moscou.

Por medio de su amigo y escritor Ivan Tourgueniev, Zola conoce al judío revolucionario y nihilista ruso Isaac Pavlovsky, exiliado en París desde 1879, memorialista y corresponsal en la capital francesa de los periódicos $L e$ courrier russe y Le Nouveau Temps, Novoié Vrémia, periódico reaccionario del editor Alexis Souvarine, cuyo nombre copia curiosamente Zola para el personaje del anarquista ruso Souvarine en Germinal. 
Estados Unidos ${ }^{86}$. El periódico Le Siècle anuncia la formación de un comité para honrar a Zola con una medalla en su honor, la medalla Charpentier. Sin embargo, Zola, esté o no equivocado, aparece ante Europa como víctima de uno de esos arrebatos de las muchedumbres que todo lo arrollan y que suele costar la vida a los que tienen el valor de oponerse a ellos, y por eso sale vencido pero levantado a una gran altura moral. Barrès ${ }^{87}$, publica al día siguiente un artículo en Le Figaro donde expresa: “...le tourbillon, la fraternité, la joie de cette fin de journée", y Henri Rochefort ${ }^{88}$ escribe: "La condamnation de Zola, c'est l'écrasement des Juifs, des étrangers, des traîtres, C'est la victoire de la France" ${ }^{\prime 89}$.

El 24 de febrero, el presidente Méline declara que se ha terminado definitivamente con el proceso de Zola y con el asunto Dreyfus y que todo debe ser olvidado, pero se equivoca, porque Dreyfus se convierte en un mito y al defenderlo se ataca al Ejército, a la Iglesia, a los prejuicios, a la injusticia y a todo lo que representa la Francia antigua ${ }^{90}$.

El escritor Anton Tchékhov considera el antisemitismo como un mal universal y varias veces ofrece sus comentarios contra él. En contacto con el caso Dreyfus y su defensa por Zola durante su visita a Francia, septiembre 1897-mayo 1898, reflexiona en público sobre él y defiende y admira a Zola por su defensa, caracterizándolo como: "Un grand écrivain qui, presque seul contre tous, tient tête à l'opinion publique et défend la cause d'un vaincu, d'un homme à terre". En la misma entrevista de Isaac Pavlovsky, el escritor ruso expresa que para un ruso es casi incomprensible este enfrentamiento entre la sociedad y el ejército, pero, a pesar de ello, "Russie a été émue profondément quand elle a constaté que l'excapitaine n'avait pas été légalement condamné" ( Zviguilsky, Alexandre: "Une interview inédite de Tchékhov sur L'Affaire Dreyfus", in Cahiers Naturalistes, n 75, 2001, pág. 387). El senador, jurista y magistrado del Tribunal Supremo ruso, Ignati Zakrevsky, bajo el seudónimo de Petchorine, publica un artículo en el n ${ }^{\circ} 27$ de Nouvelles et Gazette de la Bourse, 27 de enero-8 de febrero, titulado Zola, en el que lo defiende: “Zola, il s'y est lancé dans le feu du combat, il s'y est lancé avec le courage indomptable de l'esprit et du coeur, et il a remporté la victoire... les hommes éminents, les plus nobles, les plus talentueux envoient-ils leur salut enthousiaste des quatre coins de la terre au célèbre écrivain combattant"(op. cit. Pág. 386).

${ }^{86} \mathrm{El}$ eco y las consecuencias del caso Dreyfus llega incluso a la prensa del otro lado del Atlántico. Así, en el periódivo Nashua Daily Telegraph de la ciudad de Nashua, en el estado de New Hampshire, situado en la región de Nueva Inglaterra, aparece el 17 de septiembre de 1899, un artículo titulado, Dreyfus: un martyr enterré vivant. La réalité des faits révélée par les journaux et l'électricité, donde se recoge un sermón religioso sobre el caso Dreyfus, pronunciado por el reverendo baptista Charles Lincoln White, días después de la nueva condena de Dreyfus, el 9 de septiembre, donde fue considerado culpable pero con circunstancias atenuantes. En el artículo, en el que se presenta una condena de todos los Estados que se consideran libres y que dejan el honor del Estado y del Ejército francés en una posición poco digna en los albores del siglo XX, ya que lo que intentan con esta condena es ocultar su propio pecado y falta de honestidad de sus estamentos, se nos muestra, al mismo tiempo, la posición que una gran parte del clero norteamericano, en particular el no católico, tenía sobre el tema y su oposición clara al amtisemitismo.

El escritor Edmond Wilson en su libro Patriotic Gore, indica cómo los judíos y su doctrina religiosa son respetadas y admiradas por los habitantes de Nueva Inglaterra. Texto íntegro del discurso, traducido por Hélène Mitterand, en Les Cahiers Naturalistes, n 74, Grasset, París, 2000, págs. 375-379.

${ }^{87}$ Maurice Barrès(1862-1923), escritor y político, nacionalista, defensor del ejército, animador de un patriotismo revanchista que conduce de manera inexorable a la guerra y uno de los creadores de la Union sacrée.

${ }^{88}$ Henri Rochefort, marqués de Rochefort-Luçay(1831-1913), periodista, escritor y político de ideas republicanas, es el fundador de La Lanterne, 1868, La Marseillaise, 1869, L'intransigeant, 1881.

${ }^{89}$ BREDIN, Jean-Denis, 1998, op. cit., pág. 48.

${ }^{90}$ El 4 de abril de 1898, aparece en Le Siècle, una carta titulada Lettre d'un diplomate de Berne, donde se relata toda la verdad sobre el caso Dreyfus. La carta, tribuida a Panizzardi o a su amigo Carlos Blacker, fue escrita en 
El 23 de mayo, se abre el proceso contra Zola en Versalles, apareciendo un artículo lleno de calumnias contra el padre del novelista en Le Petit Journal, escrito por Judet y contra el que se querella Zola por difamación.

El 16 de julio, Zola publica en L'Aurore una carta abierta a Henri Brisson y el 18 de julio, se vuelve a abrir el proceso de Zola por la Audiencia de Versalles, siendo el escritor condenado de nuevo, por lo que se exilia a Londres para escapar de la prisión ${ }^{91}$. Este periodo, del 19 de julio de 1898 al 5 de junio de 1899, sin compañía familiar, suspendido de honores y con una situación material comprometida, es considerado por Zola como semanas horribles durante las cuales se siente incomprendido por la justicia y por sus compatriotas. En sus Pages d'exil, publicadas después de su muerte, se muestra desesperado ante un país en el que "la justice semblerait décidément morte" y que nunca ha sabido agradecer nada "à ceux qui l'ont sauvée de la honte"

Este proceso, al sobrepasar el ambiente judicial y convertir todo el asunto del capitán Dreyfus, sólo conocido hasta el momento en ciertos ambientes, en público y político, y su posterior condena, levanta a toda la sociedad francesa, siendo la causa de una de las crisis políticas más graves de la III República, que obliga a que las fuerzas de derecha y de izquierda se reagrupen para fortalecerse. Los intelectuales ${ }^{93}$, por una parte, desde el día

realidad por Yves Guyot y Francis de Pressensé según las notas que les administró Zola en casa de Joseph Reinach. Bertrand había contado la información de Palizzardi a cuatro personas, bajo promesa de no divulgar la información. Una de ellas es Oscar Wilde, porque según Blacker, iba a consagrar su vida a la defensa de los débiles y los oprimidos, pero, bajo la influencia de la bebida, transmitió la información a Rowland Strong y éste , a su vez, a Esterházy. Sin embargo el verdadero informador de Zola es el poeta irlandés Chris Healy, amigo íntimo de Wilde y admirador de Zola, que considera a Wilde como uno de los causantes de la puesta en libertad de Dreyfus..

Confrontar a este respecto: REINACH, Joseph. op. cit.; CONYBEARE, Frederick cornwallis: The Dreyfus Case, Londres, 1898; "La vérité au sujet de Dreyfus", el 1 de junio de 1898, en la National Review, Londres. Traducción al francés de Joseph Reinach en Le Siècle, el 5 de junio de 1898, y el ataque contra Blacker de François André de Boissandré en La Libre Parole, gracias a la información proporcionada por Esterházy y que le llevó a tener que abandonar Francia; HEALY, Chris: Confessions of a Journalist, Londres, 1904; PALÉOLOGUE, Maurice: Journal de l'Affaire Dreyfus, 1894-1899. L'Affaire Dreyfus et le Quai d'Orsay, Plon, París, 1955 (miembro de la Direction politique del Ministère des Affaires Étrangères, en el servicio de asuntos reservados, y posteriormente, representante del Ministère des Affaires Étrangères, en la revisión del proceso en el Tribunal Supremo y en el $2^{\circ}$ Consejo de guerra de Rennes).

${ }^{91}$ Zola al llegar a Inglaterra el 18 de julio de 1898, se instala en la casa "Penn", enWeybridge, ayudado por los Vizetelly. La hija del matrimonio, Violette, de 16 años, bilingüe por la influemcia de su madre francesa, Marie Tissot, se encarga de acompañar al escritor en todo momento, le traduce los periódicos que su padre Ernest envía al escritor y le hace su estancia menos dura por recordarle, tanto ella como su hermano René, a sus dos hijos en medio de este país que Zola considera en sus Pages d'exil "étranger et froid à mon coeur". Estos episodios así como la impotencia que sentía el escritor en Inglaterra por no poder defenderse directamente de los ataques que sus enemigos le dirigían y llevar él mismo la defensa de Dreyfus, han sido referidos en el libro de Ernest Vizetelly, With Zola in England.

92 JOSPIN, Lionel, op. cit., pág. 28.

${ }^{93}$ El 14 de enero de 1898, L'Aurore publica el Manifeste des Intellectuels, llamado también Manifeste des cent quatre, donde aparecen, entre otros, los nombres de los dos hermanos Proust, Charles Péguy, Octave Mirbeau, André Gide, Lucien Herr y Daniel Halévy. Marcel Proust en su obra A la recherche du temps perdu, muestra repetidas veces su indignación sobre la injusticia hecha a Dreyfus. Dos días después, L'Aurore y Le Temps, publican la Deuxième Protestation, donde se evidencia la alianza entre escritores y sabios en defensa del tema. Confrontar a este respecto, TADIÉ, J.-Y.: "Proust, le fidèle" y "Comment sont-ils devenus dreyfusards ou antidrevfusards?". in Mil neuf cent. Revue d'histoire intellectuelle. $\mathrm{n}^{\circ} 11.1994$. 
siguiente de la condena, escriben a L'Aurore para sostener la posición de Zola y, a partir del 21 de julio, Joseph Reinach publica en Le Siècle diferentes artículos en los que acusa de falseadores a Du Paty y Esterházy; por otra parte, los nacionalistas también defienden sus posturas, denunciando Barrès el 1 de febrero: "Ces aristocrates de la pensée qui tiennent à afficher qu'ils ne pensent pas comme la vile foule..., ces intellectuels seront un déchet fatal dans l'effort tenté par la société pour créer une élite"

A pesar de esta división ideológica, lo que está claro en estos momentos es el creciente poder de los medios de comunicación escrita, como dice Pierre Miquel en su excelente opúsculo dedicado al tema, "se puso de manifiesto, al obligar la prensa al gobierno, al parlamento, y a los grandes cuerpos del Estado a tomar partido en el caso, contra su voluntad e interés, que ella era en realidad más fuerte... los socialistas habían descubierto desde el "Yo Acuso" [de Zola] la fuerza revolucionaria de los periódicos; Jaurès, periodista, era más fuerte que Jaurès, diputado; Clemenceau, vencido en las elecciones, era más temible en L'Aurore que en el parlamento... era más fácil lograr la adhesión de las conciencias mediante un artículo que por medio de un discurso" 95 .

La sociedad parisina, como consecuencia de esta lucha dialéctica, se encuentra dividida en dos bandos bien diferenciados:

- Los partidarios de Dreyfus o dreyfusistas, reunidos en torno a Clemenceau ${ }^{96}$ y a Jaurès ${ }^{97}$, junto a los que se adscriben diversos colectivos que forman la representación de la

A ellos se unen otros intelectuales como Mallarmé, los vanguardistas, Bonnard, Pissarro, Signac, una gran parte de la universidad, Charles Péguy que, a través de su librería Bellais, es el difusor en el barrio Latino de los textos en favor de Dreyfus.

El periódico Le Temps fue fundado en 1829 por Jacques Coste, publicándose hasta 1842. Reaparece en 1861, como diario de la tarde, dirigido por A. Nefftzer, es uno de los grandes periódicos de fines del Segundo Imperio, convirtiéndose, bajo la dirección de Adrien Hébrard, en el órgano oficial de la IIIe République, destacando en particular por sus colaboradores y por los artículos de política exterior. Después de la guerra de 1914, se convierte en un periódico de la derecha, desapareciendo en 1942.

${ }^{94}$ BREDIN, Jean-Denis, op. cit, pág. 44.

${ }^{95}$ MIQUEL, Pierre: El Caso Dreyfus. Colección Popular. Fondo de Cultura Económica, México, pág. 133.

96 Georges Clemenceau(1841-1929), político comprometido, opuesto a la campaña nacionalista y antisemita, defensor de la separación de la Iglesia y el Estado, es el editorialista del periódico L'Aurore, que publica J'accuse de Zola. En 1901, funda el semanario Le Bloc, en 1913, el periódico L'Homme libre, que se convierte en L'Homme enchaîné a partir de agosto de 1914 y que ataca a la censura implantada No debemos olvidar que Clemenceau en su intervención a lo largo del proceso, intenta establecer un lazo de unión estable entre el ejército y la República.

Con respecto al proceso, Clemenceau que, como ya hemos dicho, llega incluso a pedir para el capitán la pena de muerte en un artículo publicado el 25 de diciembre de 1894, no cree que Dreyfus sea inocente hasta que comienza el proceso contra Zola y Ranc, Bernard-Lazare y Scheurer-Kestner le informan con documentos de las irregularidades habidas en el proceso. Desde el 1 de noviembre de 1899 hasta que el proceso termina, publica un artículo diario sobre el caso que están recogidos en su libro L'Iniquité, con un prefacio fechado el 15 de enero de 1899. El segundo volumen, titulado Injustice militaire, recoge los artículos hasta la finalización del juicio de Rennes,; el siguiente, titulado los artículos La Honte, recoge los publicados desde septiembre de 1899 a abril de 190o. Todos ellos han sido editados por Stock en 1902 y 1903.

En sus artículos en L'Aurore se felicita de la aportación de los intelectuales a la defensa del proceso: "Tous ces intellectuels, venus de tous les coins de l'horizon, qui se groupent sur une idée et s'y tiennent inébranlables"; y en un artículo que dirige a Anatole France le indica: "Nous sommes seuls, mais nous vaincrons". 
izquierda política francesa y que engloban a los intelectuales ${ }^{98}$, los socialistas, los radicales, los republicanos moderados y los antimilitaristas, reunidos bajo el nombre de la Liga de los derechos del hombre y del ciudadano ${ }^{99}$. Todos ellos, defensores de una sociedad laica y antimilitar, denuncian la alianza establecida entre el ejército y la Iglesia y reivindican los derechos del hombre, la libertad individual y la búsqueda de la verdad y de la justicia, reclamando la revisión del proceso.

- Los antidreyfusistas, reunidos en torno a Barrès -que acusa a Dreyfus y a sus seguidores de la separación existente entre el pueblo francés y su ejército-, a Déroulède, ${ }^{100}$ y a Mun: Los tres con la ayuda del periódico católico La Croix y de L'Action Française de Charles Maurras -que denuncia la existencia de un complot judeo-masónico-, representan a la derecha política. Dentro de ellos se encuentra la derecha nacionalista, antisemita y clerical, agrupada bajo el nombre de Ligue de la patrie française ${ }^{101}$ y La Ligue des patriotes de Paul

97 Jean Jaurès(1859-1914), filósofo, historiador, político y hombre de Estado, defensor de la unidad del movimiento socialista, se enfrenta a J. Guesde pero sus tesis triunfan a partir de la constitución del SPIO. Aunque al principio no tenía clara su postura en cuanto a la inocencia del capitán Dreyfus por crer que es un ajuste de cuentas entre burgueses, publica, en 1898, Preuves, donde toma posición a favor de la inocencia de Dreyfus.

Es también el fundador del periódico L'Humanité, 1904, órgano oficial del partido socialista hasta 1920. Después de la I Guerra Mundial, 1923, bajo la dirección del político comunista Marcel Cachin, es el propagador de estas ideas.

${ }^{98} \mathrm{La}$ intervención en el proceso Dreyfus del escritor Emilio Zola, produce una reacción positiva entr sus compañeros, iniciándose una época de agrupamiento y de compromiso político y social por parte de los intelectuales que se continúa de manera ininterrumpida hasta la época de Jean-Paul Sartre en que se instaura un cierto aislacionismo político e ideológico.

${ }^{99}$ La Ligue des droits de l'homme et du citoyen, se funda en París, en febrero de 1898, auspiciada por el parlamentario republicano L.Trarieux y que reagrupa a toda la izquierda francesa que, a causa del proceso contra E. Zola, por la publicación del J'Accuse, está persuadida de la inocencia de Dreyfus y solicita la revisión del proceso. Su finalidad es defender los derechos y las libertades del hombre y del ciudadano, frente a las arbitrariedades de la justicia y del poder político. Controlada primero por los radicales que se oponen a la derecha nacionalista, clerical y a menudo antisemita, pasa a manos, a partir de 1933, de los socialistas, jugando un papel fundamental a lo largo de la III República, por su lucha en favor de lo laico, de la democracia, de la igualdad y del pacifismo. Sus ideas aparecen publicadas y defendidas en los Cahiers des droits de l'homme, fundados en 1920, y en La Quotidienne, fundado en 1923.

${ }^{100}$ Paul Déroulède(1846-1914), escritor y hombre político, defensor de un patriotismo nacionalista y revanchista, es el fundador y el presidente de la Ligue des pattriotes, 1882.

${ }^{101}$ La Ligue d'action française(1908-1944), nace bajo la protección del Comité d'action française, creado por Pujo y Vaugeois, fundadores también del periódico bimensual L'Action française, protegido y animado por Ch. Maurras, J. Bainville y L. Daudet, que aparece como tribuna de la extrema derecha a partir del caso Dreyfus. Este comité, nacionalista y antidreyfus, se transforma en la Ligue d'action française. Bajo la influencia de Maurras y apoyado por la parte más conservadora de la burguesía francesa, el movimiento se convirtió en el defensor del nacionalismo íntegro, de la monarquía hereditaria antiparlamentaria y descentralizada, erigiendo a la Iglesia católica como la defensora de este orden y atacando a la República, a los judíos y a los francmasones.

Los dos periódicos que defienden abiertamente esta línea nacionalista y monárquica son L'Action Française y La Croix.

- L'Action française, aparece primero como publicación bimensual, convirtiéndose en cotidiano en 1908. Este periódico es el instigador, en noviembre de 1908, bajo los auspicios de Maxime Real del Sarte y de Lacour, de los Camelots du Roi, recrutados entre los estudiantes y los discípulos de Maurras y encargados, en un principio, de la venta y distribución del periódico, transformándose posteriormente, en grupos de combate monárquicos. Estos grupos fueron disueltos en 1936. 
Déroulède, defensora ante todo del interés superior de la patria y del honor del ejército antes que de la justicia. Este grupo es el causante de los movimientos antisemitas que surgen en Francia en este periodo y que cristalizarán a lo largo de la primera y segunda Guerras mundiales. Consideran que Dreyfus es un espía y un traidor y que por su origen judío amenaza la integridad nacional.

A esta clasificación binaria hay que añadir además otros grupos que se proclaman independientes, como el socialista que, el 19 de enero, en La Petite République, con las firmas de Jules Guesde ${ }^{102}$, René Viviani103, Alexandre Millerand104 y Jean Jaurès, rehusan cualquier tipo de compromiso sobre este asunto. Sin embargo, a partir del 22 de enero y, a causa de los artículos publicados en La Petite République, Jaurès publica Les Preuves, 1898, en el que cambia su opinión e intenta demostrar la inocencia de Dreyfus.

La familia Dreyfus, por medio de la esposa del capitán, Lucie Hadamard, interpone de nuevo la petición de un nuevo juicio y la revisión de las pruebas el 5 de julio de 1898. El ministro de la Guerra, Godeffroy Cavaignac, solicita un estudio profundo del documento acusador por los expertos.

En agosto de 1898, se descubre que el documento sobre el que se basa la acusación de Dreyfus ha sido fabricado por el coronel Hubert Robert Henry, en el que menciona el

- La Croix, es un periódico serio de tirada mensual, dirigido a una élite, a un público escogido, publicado en 1880 por los padres asuncionistas Picard y Vincent de Paul Bailly. Después de la muerte del fundador de la congregación, el abate Enmanuel d'Alzon, y de la expulsión de las congregaciones en 1881, desaparece, pero reaparece como publicación periódica el 16 de junio de 1883, dedicándose a publicar asuntos sensacionalistas. Defensor, en un primer momento, de la tradición católica, frentre a los valores laicos y republicanos del nuevo regimen, por las corrientes del momento se convierte en un periódico antisemita, siguiendo la línea de La France juive, de Drumont, y de La Libre Parole, justificando a través del caso Dreyfus sus excesos y su xenofobia. Según los asuncionistas, los judios están integrados en el denominado "trío del odio":

$1^{\circ}$.- El protestantismo, que quiere arruinar al catolicismo, es decir al alma de Francia.

$2^{\circ}$.- El judaísmo, que quiere apoderarse de las riquezas nacionales, del cuerpo de Francia.

$3^{\circ}$.- La francmasonería, linea de unión natural de las dos corrientes anteriores, que quiere destruir, al mismo tiempo, el alma y el cuerpo de Francia (Confrontar: SOBLIN, Pierre: La Croix et les Juifs, Grasset, París, 1967, p. 117). .

Después de la condena papal de L'Action française en 1936, periódico cercano a él en ideología, adopta una linea más abierta y sostiene la creación de la Jeunesse ouvrière chrétienne JOC) y de la Jeunesse ouvrière chrétienne féminine(JOCF), movimiento de Acción católica destinado a la formación (política y sindicalista de los jóvenes del medio obrero. Creado en Bélgica, en 1925, por el abad Cardijn, desarrollándose posteriormente en los arrabales parisinos gracias a la acción del abad Guérin.

Este periódico pertenece al grupo Bayard-Presse, publicándose en la actualidad bajo el nombre de La CroixL'Événement, siendo el principal periódico católico francés.

102 Jules Guesde (1845-1922), político francés que, a través del primer periódico marxista francés, L'Égalité, 1877 1883, extiende en Francia las ideas marxistas. Con el socialista Paul Lafargue(1842-1911), miembro de la Primera Internacional y yerno de Carlos Marx, organiza el Parti ouvrier, 1882, que se convierte en el Parti socialiste de France, 1902. En 1905, se transforma en el Parti socialiste SFIO, por la fusión en el Parti socialiste français de Jaurès.

${ }^{103}$ René Viviani (1863-1925), político y diputado socialista francés, fundador en 1922 del Parti républicain socialiste. Colabora con La Petite République, La Lanterne y L'Humanité.

${ }^{104}$ Alexandre Millerand(1859-1943), político y hombre de Estado. Colabora con Clemenceau en la publicación del periódico La Justice. Evoluciona desde posiciones radicales a socialistas de las que se aleja a partir de 1905, momento de la formación del Parti socialiste unifié. Después de la primera Guerra Mundial elabora el programa del Bloc national, de carácter conservador. 
nombre de Dreyfus con el fin de inculparlo. La aparición de la carta que es posterior al proceso, 1898, es considerada como falsa, Henry se confiesa culpable ante el ministro de la Guerra, Cavaignac, al que ya su ayudante Louis Cuignat le había demostrado la falsedad del documento elaborado supuestamente por Dreyfus. Al comprobarse la similitud de la carta con su letra, es condenado y encerrado en la prisión militar de Mont-Valérien. La agencia de prensa Havas ${ }^{105}$, publica el 39 de agosto la siguiente información: "Aujourd'hui, dans le cabinet du ministre de la Guerre, le lieutenant-colonel Henry a été reconnu l'auteur de la lettre en date d'octobre 1896, où Dreyfus est nommé. Le ministre de la Guerre a ordonné immédiatement l'arrestation du lieutenant-colonel Henry, qui a été conduit à la forteresse du Mont Valérien"106.

El día después de su internamiento, el 31 de agosto de 1898, se suicida, siendo alabado por la prensa antidreyfus. La Libre Parole lo califica como: "une âme simple, un fervent de

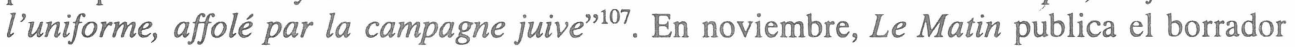
de la carta falsa elaborado por el teniente coronel.

El diputado y redactor jefe de La République française, el judío Joseph Reinach ${ }^{108}$, al defender a Dreyfus, acusa también a Henry de haber sido cómplice de Esterházy en la entrega de importantes documentos políticos a Schwartzkoppen ${ }^{109}$. La mujer de Henry intenta llevar a juicio al diputado, para mostrar lo absurdo de sus acusaciones, y levanta, al mismo tiempo, un monumento a su esposo en el cementerio, sufragado por una suscripción popular llevada a cabo por La Libre Parole y que se eleva a la cantidad de 131.000 francos ${ }^{110}$. Charles Maurras declara a Henry héroe nacional.

El 5 de junio de 1899, el mismo día de la vuelta de su destierro, en el artículo Justice, Zola confiesa haber conocido con anterioridad la culpabilidad de Henry, pero que, al no tener pruebas de ello, no se atrevió a citar su nombre en su artículo J'Accuse, sintiéndose ahora culpable de su debilidad.

El suicidio del teniente coronel levantó una fuerte polémica en la sociedad y el ataque de los dreyfusistas provocó la dimisión del general de Boisdeffre, jefe del Estado mayor el mismo día de la condena del teniente coronel Henry, del ministro de Travaux publics, el senador Tillaye, del ministro de la Guerra, Cavaignac, hostiles a la revisión del proceso. El

${ }^{105}$ La agencia de prensa Havas, es la primera agencia francesa de información política y de publicidad. Fue creada
en París, en 1835, por Charles Henri Havas (1785-1858) y sostenida por el gobierno de Louis-Philippe. Su hijo
Auguste siguió como director con la misma línea de información política hasta 1879, fecha en la que se transforma
en sociedad de accionistas. La empresa se denomina después de 1944 Agence France Presse, convirtiéndose el
Estado en su accionista mayoritario y privatizándose de nuevo en 1987. Actualmente es el primer grupo
multimedia francés.

${ }^{106}$ http://www.adv.fr/judaisme/perso/dreyfus/affaire2.htm, pág. 3.

${ }^{107}$ Ibidem, pág. 3.

${ }^{108}$ Este político escribe una Histoire de l'Affaire Dreyfus, en 7 tomos.

${ }^{109}$ Artículo publicado el 7 de noviembre en Le Siècle y el 8 de diciembre retoma el tema y establece de nuevo su acusación.

${ }^{110}$ Pierre Quillard publica Le Monument Henry, donde aparece una lista clasificada y detallada de las personas que contribuyeron a la construcción del monumento, con los comentarios correspondientes a cada una de ellas. Esta cantidad está también a la disposición de la viuda de Heny para que se querelle contra Reinach. 
gabinete Brisson tuvo que acordar la revisión del proceso. El 5 de junio, Dreyfus recibe una nota en su celda por la que se le comunica la revisión de su juicio, la anulación del anterior, el levantamiento de las penas impuestas en el anterior juicio, su rehabilitación y su traslado a Europa. Llega a Quiberon, en Bretaña, el 1 de julio de 1899.

Hasta el 18 de julio de 1899 Esterházy no admite su culpabilidad, pero indica, en un artículo aparecido en Le Matin este mismo día, que ideó todo el plan bajo la presión de sus superiores militares para poder condenar a un judío ${ }^{111}$. Admitida la revisión por el Tribunal Supremo, se celebra un nuevo juicio entre el 7 de agosto y el 9 de septiembre de $1899^{112}$, ante el Consejo de guerra del décimo cuerpo del ejército de Rennes, donde el jefe del servicio de identidad judicial de París, Alphonse Bertillon ${ }^{113}$, intenta establecer la culpabilidad de Dreyfus, fundamentándose en cálculos establecidos a partir de leyes de distribución y de probabilidad. Un grupo de expertos requeridos por el Supremo, Darboux ${ }^{114}$, Appell ${ }^{115}$ y Poincaré ${ }^{116}$, después de estudiar el informe Bertillon deciden que las teorías sobre las que éste fundamenta su acusación no tienen ninguna justificación científica seria. Sin embargo, es declarado de nuevo culpable, pero con circunstancias atenuantes, siendo condenado sólo a diez años de reclusión y preparando con ello su próxima liberación. El 12 de septiembre, Zola escribe en L'Aurore, el artículo Le cinquième acte, donde se asusta del estado en que se encuentra en la actualidad la justicia y la sociedad francesas: "...ce que je crie c'est la détresse de notre généreuse et noble France, c'est l'effroi de l'abîme où elle roule"117. Ante esta nueva condena Zola huye de nuevo a Londres.

Unos días después, el 19 del mismo mes, Dreyfus fue liberado por el presidente de la República, el republicano moderado Émile Loubet ${ }^{118}$, a petición del gobierno, aunque sigue siendo considerado como culpable, desde un punto de vista oficial. A partir de este momento Dreyfus se convierte en un mártir y en un símbolo para los liberales, pero sigue siendo considerado como un traidor por los reaccionarios. El 29 de septiembre, también en L'Aurore, el 22 de este mes, Zola publica su Lettre à Madame Alfred Dreyfus: "Il peut

\footnotetext{
${ }^{111}$ Ante la posibilidad de la prisión, Esterhazy huye a Londres y vive allí hasta su muerte acaecida en 1934, 25 años después de su declaración de culpabilidad.

${ }^{112}$ Sobre la revisión del proceso Dreyfus de Rennes, confrontar el texto mecanografiado publicado en dos tomos por el editor Stock en París en 1900.

${ }^{113}$ Alphose Bertillon(1853-1914), es el creador de la "anthropométrie" o "bertillonnage", método para identificar criminales.

${ }^{114}$ Gaston Darboux(1843-1917), matemático, geómetra y académico, creador de un método de integración.

${ }^{115}$ Paul Appel(1855-1930), matemático, autor de tratados de mecánica racional y funciones elípticas.

${ }^{116}$ Henri Poincaré(1854-1912), matemático universal que aplica estos principios a la física.

${ }^{117}$ BREDIN, Jean-Denis, op. cit. pág. 51.

${ }^{118}$ Elegido presidente a la muerte de Félix Faure, 1899, Loubet(1838-1929), se opuso a los movimientos antidreyfus, siendo incluso agredido por ello en las carreras de Auteuil.
} 
dormir tranquille et confiant, Madame, dans le doux refuge familial, réchauffé par vos mains pieuses. Et comptez sur nous pour sa glorification"119.

A lo largo de los 7 años que van desde su liberación a su rehabilitación, Alfred Dreyfus lucha por mostrar la falsedad de las acusaciones que se hicieron contra él y por conseguir su reintegración en el ejército.

El 14 de diciembre de 1900, el gobierno de izquierda de Waldeck Rousseau ${ }^{120}$ promulga la amnistía para todos los delitos relacionados con el asunto Dreyfus: Zola está amnistiado. El 22 de diciembre publica en L'Aurore, una Lettre à M. Loubet, Président de la République, donde explica cómo la falta de respuesta de su antecesor el presidente Felix Faure, a su carta del 13 de enero de 1898, ha motivado todo un cambio político y de mentalidad en la sociedad francesa: "Tout le mouvement de défense républicaine, est né de là. Et si la France est sauvée du long complot de la réaction c'est à l'affaire Dreyfus qu'elle le devra"121.

La rehabilitación de Zola como defensor de los débiles comienza a establecerse desde el momento de su muerte. En la ceremonia de su entierro en el cementerio Monmartre, Anatole France, en su discurso funerario, le honra y le evidia al mismo tiempo: "Envionsle. Sa destinée et son coeur lui firent le sort le plus grand: il fut un moment de la conscience humaine"122

En abril de 1903, el caso no está aún olvidado. Jean Jaurès vuelve a relanzar el tema Dreyfus en la Cámara legislativa, atacando y levantando a la derecha por su prensa llena de invenciones y mentiras: "Quel triomphe, pour moi, de vous faire hurler en vous citant votre presse!" 123 . Este hecho hace que el general André124, ministro de la Guerra, abra una encuesta administrativa que terminará con la revisión del proceso de Rennes, acordado en 1904. En julio de 1906, el Tribunal Supremo anula el juicio de Rennes, declarando la amnistía total para todos los participantes. Pero Pressensé ${ }^{125}$ se opone a esta decisión, ya que le parece escandaloso que militares de alto grado como Lauth y Rollin, acusados por el procurador general Badouin de falso testimonio e impostura, así como muchos otros que ya

${ }^{119}$ BREDIN, Jean-Denis, op. cit. pág. 51.

${ }^{120}$ Pierre Waldeck-Rousseau(1848-1904), político y hombre de Estado perteneciente a la izquierda moderada. Durente su presidencia, 1899-1902, se opuso al nacionalismo de derechas con un gabinete de Defensa Nacional, formado por Galliffet, ministro de Guerra, y Millerand, que decidió la revisión del proceso y los inculpados.

${ }^{121}$ BREDIN, Jean-Denis, op. cit. pág. 52.

${ }^{122}$ Chronologie de l'Affaire Dreyfus, in www.cahiers-naturalistes. Com/chronologie_dreyfus.htm, pág. 10.

${ }^{123}$ LIPSCHUTZ, Léon: “Il y a soixante ans... La liquidation de l'affaire Dreyfus”, in Cahiers Naturalistes, $\mathrm{n}^{\circ} 31$, Fasquelle, Pariís, 1966, pág. 82.

${ }^{124}$ Louis André (1838-1913), político y hombre de Estado, reemplaza al general Galifet en el ministerio, 1900. Es el creador del Sistema de fichas, por el que los militares pueden ascender según sean sus opiniones recogidas en fichas, en el terreno político y religioso. Este asunto levantó a los conservadores contra él y le obligó a presentar su dimisión.

${ }^{125}$ François Duhault de Préssensé(1853-1914), escritor, periodista y político liberal. Después de dedicarse a la diplomacia la abandona para volcarse en el periodismo, trabajando en Le Parlement, La République Française y Le Temps en la sección de extranjero. Se interesó vivamente en el caso Dreyfus, trabajando en su defensa. Publica Son héros. Le lieutenant colonel Picquart, 1898. 
están jubilados, hayan seguido ejerciendo sus puestos y hayan pasado por el ejército sin recibir ningún castigo. Messimy, en nombre de la comisión del ejército, propone la rehabilitación de Dreyfus y su reintegración en el ejército, siendo promocionado a jefe de batallón y nombrado Caballero de la Legión de honor; al mismo tiempo, Messimy propone que el teniente coronel Georges-Marie Picquart vuelva a Francia y que sea nombrado general de brigada, aunque su nombramiento es fuertemente contestado por la derecha, indicando en la Cámara Denys Cochin ${ }^{126}$ que no puede votar el reconocimiento de un militar que ha escrito artículos contra sus compañeros y sus jefes. Finalmente, el presidente Clemenceau, le nombra ministro de la Guerra de su gabinete ${ }^{127}$.

Al final de la sesión del Senado, su presidente, Antonin Dubost ${ }^{128}$, lee la petición de la Cámara de diputados, en nombre de su presidente M. Gaudin de Villaine ${ }^{129}$, solicitando el traslado de las cenizas de Émile Zola al Panthéon. El debate se remite al mes de diciembre y después de varias intervenciones, entre otras la del derechista Emmanuel de Las Cases o la de Ponthier de Chamallard ${ }^{130}$, en contra, y las de Eugène Lintilhac ${ }^{131}$ y del presidente Clemenceau, a favor, se vota la proposición, siendo aprobada por el Senado el día 12 de diciembre de 1906.

Con respecto a las publicaciones aparecidas sobre el tema, el 13 de julio, La Libre Parole publica: "Le triomphe des Juifs: Dreyfus réhabilité"132.

El 17 de julio, sobre el traslado de las cenizas de Zola, dice el mismo periódico: "Aujourd'hui, le trop célèbre pornographe est jugé digne du Panthéon, mais par la valetaille dreyfusarde et non point par les écrivains"133.

En el mismo sentido crítico aparecen artículos en La Croix y Le Gaulois.

En 1930 se publicaron los cuadernos del agregado alemán Max von Schwartzkoppen en los que se prueba definitivamente la inocencia de Dreyfus y la culpabilidad del comandante

\footnotetext{
${ }^{126}$ Este político y hombre de Estado(1851-1922), es diputado por París como miembro destacado de la derecha monárquica y antidreyfus. Por sus ideas conservadoras, es el defensor de la Iglesia frente a la política anticlerical del gobierno republicano.

${ }^{127}$ Es penoso que Zola, tan luchador y defensor de los principios, no pudiese conocer en vida la absoluta inocencia de todos los procesados y el reconocimiento debido a ellos y a él mismo. Su muerte, en condiciones inciertas, accidente, o asesinato, no hace más que oscurecer un poco más este asunto tan farragoso para la política y el Ejército francés.
}

${ }^{128}$ Henri Antoine Dubost, llamado Antonin(1844-1921), político, perodista y hombre de Estado, de tendencia socialista radical, fue ministro de Justicia, 1893-94, y senador a partir de 1897.

${ }^{129}$ Adrian Gaudin de Villaine(1851-1936), escritor y político. En 1885 es diputado y posteriormente senador por el distrito de La Manche. Escribe Espionnage allemand en France, 1916.

${ }^{130}$ Heri Charles Ponthier de Chamaillard(1848-1908), Escritor y político monárquico, es senador desde 1897, participando de manera activa en los debates de la Cámara.

${ }^{131}$ Eugène François Lintilhac(1854-19), literato y senador, votó la separación de la Iglesia y el Estado en 1904. Escribe Histoire générale du théâtre français y Théâtre sérieux du Moyen Âge(1904).

${ }^{132}$ LIPSCHUTZ, Léon: "Il y a soixante ans ... La liquidation de l'affaire Dreyfus", in Cahiers Naturalistes, $\mathrm{n}^{\circ} 31$, Fasquelle, Pariís, 1966, pág. 77.

${ }^{133}$ Ibidem, pág. 78. 
Esterházy. En ellos se indican las seis visitas que el comandante hace al agregado militar en la embajada alemana, entre los meses de julio y septiembre de 1984:

1.- El 20 de julio, Esterházy se presenta sólo como un oficial en activo del Estado Mayor francés.

2.- El 27 de julio, como el conde Walsin-Esterházy, ofrece al agregado alemán el cuaderno de movilizaciones del ejército francés y solicita por su información 2.000 francos mensuales. Su petición no es tenida en cuenta.

3.- El 13 de agosto, ante esta nueva visita, el agregado alemán ledevuelve su cuaderno y decide romper las relaciones.

4.- El 15 de agosto, Esyerházy ofrece esta vez los planos del plan de movilización de la artilleria francesa. Schwartzkroppen lo acepta y le paga 1.000 francos.

5.- El 1 de septiembre, vuelve con numerosos documentos de interés militar.

6.- El 5 de septiembre, presenta al diplomático alemán un informe detallado de las maniobras que el ejército francés ha llevado a cabo y en las que él mismo había participado $^{134}$.

El 19 de noviembre de 1898 aparece el primer fascículo de Dessous de l'Affaire Dreyfus, escrito por Esterházy, donde explica todos los entresijos del caso y los implicados en él.

El 19 de julio de 1899, por primera vez, Esterházy se declara culpable de la elaboración del "bordereau", pero indica que lo realizó bajo la orden de sus superiores militares.

Vamos a citar a continuación el resumen cronológico de los artículos publicados por Émile Zola en torno al tema Dreyfus:

1897:

\section{Le Figaro:}

16 de mayo: Pour les Juifs.

25 de noviembre: M. Scheurer-Kestner.

1 de diciembre: Le Syndicat.

5 de diciembre: Procès-verbal.

Fasquelle:

${ }^{134}$ Por las fechas de las visitas y por dos cartas que el mismo Esterházy dirige al comandante Carrière y al Garde des Sceaux, podemos deducir que el famoso "bordereau" se redacta en los primeros días del mes de septiembre.

- En la primera de ellas, escrita el 8 de agosto de 1890, expone al comandante el plan del coronel Sandherr para que se ponga en contacto con el agregado alemán y cómo el mismo coronel le indica el nombre del oficial al que va a imputársele la falta y le dicta lo que tiene que poner en el "bordereau".

- En la segunda, escrita el 19 de marzo de 1900, confiesa que todas las medidas han sido tomadas para que el "bordereau" tenga una fecha precisa.

Se deduce por ello, que el "bordereau" tuvo que ser escrito después del 5 de septiembre, fecha de la última visita de Esterhazy al agregado alemán. Como este papel iba a ser utilizado sólo en régimen interno, Esterhazy no tuvo que enmascarar la letra ni tomar ninguna precaución. Sobre las fechas del "bordereau" confrontar Les Cahiers Naturalistes, $n^{\circ}$ 62, págs. 35-57. 
14 de diciembre: Lettre à la jeunesse.

1898:

Fasquelle:

6 de enero: Lettre à la France.

L'Aurore:

13 de enero: J'accuse.

L'Aurore:

16 de julio: Lettre ouverte à Henri Brisson.

Le Figaro.

25 de noviembre: La vérité est en marche, et rien ne l'arrêtera.

1899:

Le Figaro:

5 de junio: Justice.

L'Aurore:

12 de septiembre: Le cinquième acte.

L'Aurore:

29 de septiembre: Lettre à Madame Alfred Dreyfus.

1900:

L'Aurore:

29 de mayo: Lettre au Sénat.

L'Aurore:

14 de diciembre: Lettre à M. Loubet, Président de la République.

1901:

1 de febrero: La vérité en marche, conjunto de artículos escritos durante todo el proceso Dreyfus.

Las publicaciones periódicas sobre el "affaire Dreyfus" siguen apareciendo con regularidad hasta 30 años después de su conclusión. Así entre 1928 y 1936 tenemos referencia de los siguientes artículos:

- 18 de enero de 1928, Valmy-Baisse, Le 30e. Anniversaire de J'accuse, en La Rumeur.

- 21 de enero, Georges Pioch, Le 30e. Anniversaire de J'accuse, en La Volonté.

- 3 de octubre, Maurice Le-Blond, L'émotion soulevée par J'accuse, en La Volonté.

- 4 de octubre, el artículo anterior en Le Soir.

- 7 de octubre, Charles de Rouvre, Émile Zola, professeur de justice, en La Rumeur.

- 21 de febrero de 1929, Camille Ferdy, Émile Zola et l'"Affaire", en le Petit provençal.

- 16, 23 y 30 de junio, Victor Méric, Une vieille Affaire(l'Affaire Dreyfus), en Le Progrès civique.

- 5 de julio, Guermanoff, Émile Zola et les juifs russes, en L'Univers israélite.

- 28 de octubre, C.O.X.., Zola et l'Affaire Dreyfus, en Le Populaire de Nantes.

- 20 de enero de 1934, Alexandre Zévaès, L’Affaire Dreyfus, en Germinal. 
- 10 de diciembre, Charles Chassé, Une résurrection de l'Affaire Dreyfus, en La Dépêche de l'Ouest.

- 15 de diciembre, Alexandre Zévaès, La politique et le romancier, en L'Agence technique de la Presse.

- 21 de enero, Urbain Gohier, Qui a écrit J'accuse? Émile Zola, François Coppée, Bernard Lazare?, en L'Ordre.

- 10 de marzo de 1935, Robert Bourget-Pailleron, Les idées de Zola, en La Presse.

- 11 de octubre de 1936, Jean Cassou, Zola et la liberté; Georges Pioch, Une lettre inédite de Jaurès â Zola, y Léon Blum, Extrait des Souvenirs sur l'Affaire, en Le Populaire ${ }^{135}$.

- 1 de febrero de 1937, Auriant, Un portrait inconnu d'Émile Zola, par Charles Maurras, en Mercure de France.

- 9 de marzo, Auriant, Une condamnation fort honorable, en Le Voltaire.

- 1 de julio, H.S.Salemson, Un film sur l'affaire Dreyfus, en L'Intransigeant.

- 12 de agosto, Alexandre Zévaès, Émile Zola en Cour d'Assises, en La Défense.

- 27 de agosto, Armand Charpentier, Quelques intellectuels que "l'affaire" conduisit vers la politique, en L'Oeuvre.

- 1 de enero de 1938, Gabriel Brunet, Le quarantième anniversaire de J'accuse, en la Agence technique de la Presse.

- 13 de enero, Alexandre Zévaès, Le quarantenaire de J'accuse, en L'Oeuvre. También aparece en L'Ère nouvelle, Ce Soir, La Concorde, L'Oeuvre.

- 16 de enero, Pierre Paraf, Les quarante ans de J'accuse, en La République.

- 19 de enero, Émile Pillias, Le quarantième anniversaire du procès intenté à Émile Zola, en L'Ordre.

- 22 de enero, Armand Charpentier, A propos du quaratième anniversaire de J'accuse.

Ce que l'on ne sait pas, en Agence technique de la Presse.

- 22 de enero, Armand Charpentier, Il y a quarante ans que Zola écrivit J'accuse.

- 29 de enero, Armand Charpentier, Léon Daudet aux pieds de Zola (copie d'une lettre de Léon Daudet à É. Zola, du 17 décembre 1899), en Le Voltaire.

- 12 de febrero, Saint-Georges de Boubélier, Il ya quarante ans, Émile Zola criait: J'accuse!, en Paris-Soir.

- 19 de febrero, André Billy, Paris-Soir et l'affaire Dreyfus, en La République.

- 26 de febrero, Armand Charpentier, Le quarantenaire du procès Zola, en La République.

- 24 de noviembre, J. Du Paty de Clam, Le quaratième anniversaire de J'accuse: une lettre de M. J. Du Paty de Clam, en La France de Bordeaux.

- 31 de diciembre, Armand Charpentier, Du Paty de Clam fut-il "l'ouvrier diabolique de

l'Affaire?", en Agence technique de la Presse ${ }^{136} 137$.

${ }^{135}$ Para confrontar artículos sobre otros temas, LE BLOND, Maurice y Jean-Claude: "Émile Zola dans la presse parisienne de l'entre deux guerres”, in Cahiers Naturalistes, n 31, Fasquelle, París, 1966, págs. 86-94; n 35, 1968, págs. 65-80; nº 38, 1969, págs. 169-190. 
${ }^{137}$ Artículos aparecidos en Les Cahiers Naturalistes, sobre el caso Dreyfus desde 1955 a 1997, confrontar la lista elaborada por Alain Pagès, Cahiers Naturalistes, $n^{\circ} 72$, Grasset-Fasquelle, París, 1998, pp. 443-445.

Obras, artículos y emisiones de radio y televisión, con motivo del centenario de "J'accuse", lista elaborada por Philippe Oriol y Alain Pagès en Cahiers Naturalistes, nº 72, Grasset-Fasquelle, París, 1998, pp. 435-442.

Para confrontar artículos sobre otros temas, LE BLOND, Maurice y Jean-Claude: "Ëmile Zola dans la presse parisienne de l'entre deux guerres", in Cahiers Naturalistes, $n^{\circ} 31$, Fasquelle, París, 1966, pp. 86-94; n 35, 1968, pp. 65-80; n 38,1969 , pp. 169-190.

Sobre información bibliográfica, Pierre Victor Stock ha publicado la primera bibliografía sobre el caso desde 1900 y Paul Desachy la ha completado. Léon Lipschutz ha estructurado una bibliografía temática y analítica y Jean-Max Guieu ha elaborado la primera bibliografía informatizada con más de 5.000 referencias ordenadas alfabeticamente.

Jean-Max Guieu ha editado los trabajos presentados en los dos congresos commemorativos llevados a cabo en Estados Unidos en 1998 que tenían por finalidad establecer la unión entre el caso Dreyfus y la historia de Francia, viendo cómo este caso de antisemitismo había sido uno de los causantes de la descomposición republicana y que llevó directamente al periodo de colaboración con el gobierno alemán. El primero, realizado en la Columbia University de Nueva York, organizado por Henri Mitterand y Jean-Yves Mollier, con el título " $L$ 'Affaire Dreyfus: Mémoire et Histoire en France et aux États-Unis". El segundo, organizado por Jean-Max Guieu en la Georgetown University de Washingtown, con el título "The Dreyfus Case: Human Rights versus Perjudice, Intolerance and Demonization".

Vincent Duclert ha editado los trabajos presentados en el coloquio celebrado en Médan, realizado conjuntamente por la Société littéraire des Amis d'Émile Zola y la Société d'études jaurésiennes el 30 de mayo de 1998, que trabajó conjuntamente la entrada del escritor en el dreyfusismo y la transformación obligada de Jaurès, por su fracaso electoral, de político a director de periódico e historiador.

- Resumen de los hechos más importantes del caso Dreyfus.

Alfred Dreyfus (1859-1935).

1894:

Septiembre: El Servicio de información del ejército intercepta un documento en el que se indica que una información reservada de defensa va a ser enviada a la embajada alemana en París.

Octubre: El capitán Alfred Dreyfus, oficial de origen judío, es acusado de alta traición y arrestado por el comandante du Paty de Clam.

Diciembre: Dreyfus es condenado a cadena perpetua, degradado y deportado a la Isla del Diablo(Guayana francesa).

1895:

Julio: El comandante Picquart, es nombrado jefe del Servicio de información.

1896:

Marzo: Reconocimiento del "petit bleu", carta-telegrama de la embajada alemana al comandante Esterházy. Picquart se convence de la culpabilidad de Esterházy. Enfrentamiento a los altos militares y destierro en África.

Noviembre: El comandante Henry redacta un falso documento para acusar a Dreyfus.

Bernard Lazare, escritor y periodista judío de extrema izquierda, es el primer intelectual partidario de Dreyfus: Une erreur judiciaire. La vérité sur l'affaire Dreyfus

1897:

Junio: El vicepresidente del Senado, Auguste Scheurer-Kestner, judío protestante y liberal, defiende a Dreyfus ante el presidente Félix Faure que rechaza su alegato en octubre.

Noviembre: Mathieu Dreyfus acusa públicamente a Esterházy de ser el culpable del documento.

Primer artículo de E. Zola en favor de Dreyfus, 25 de noviembre, en Le Figaro: La vérité est en marche, et rien ne l'arrêtera".

1898:

Los intelectuales franceses se movilizan en favor de Dreyfus: Charles Péguy, Marcel Proust, André Gide, Mallarmé.

Enero: Esterházy es absuelto por el Consejo de guerra.

13 de enero, E. Zola publica en L'Aurore: J'accuse.

Febrero: El Tribunal Supremo del Sena condena a Zola a un año de prisión y a 300.000FF. de multa, por difamación.

Julio: Revisión del proceso y nueva condena. Destierro y huida a Inglaterra.

Agosto: El coronel Henry declara haber elaborado un documento falso, condena y dimisión. Suicidio en la prisión de Mont-Valérien. 
Terminaremos el presente trabajo con dos citas que refrendan la importancia que este "affaire" Dreyfus tuvo para la sociedad francesa, las pasiones que levantó, su sentido de culpabilidad por una gran parte de la sociedad francesa que le hace, cien años después, erigir una estatua a este hombre ultrajado en los jardines de las Tuileries, uno de los más visitados por los turistas ${ }^{138}$, y su continua actualidad, puesto que hoy en día siguen surgiendo aún testimonios de xenofobía en todas las sociedades:

- Una del propio Zola sobre su esperanza en el descubrimiento de la verdad: “...j'aurais le coeur brisé si je n'étais pas assuré, ainsi que je vous le répète encore, que la vérité se fera un jour. Un grand peuple qui a soif de justice finira par rencontrer la vérité, peut-être tardivement, mais sûrement, aussi sûrement que la vague brise le roc" ${ }^{139}$.

- Una frase de Charles Péguy, rememorada por M. Alain Richard, ministro de Defensa francés, que nos pone en evidencia cómo en la actualidad, más de cien años después de su comienzo, este asunto político, social y judicial despierta aún controversias entre la sociedad: "Plus cette affaire est finie, plus il est évident qu'elle ne finira jamais"140.

\section{9:}

Junio: Zola vuelve del destierro.

Agosto: Revisión del proceso de Dreyfus, en Rennes. Nueva condena con circunstancias atenuantes.

Septiembre: Alfred Dreyfus es amnistiado por el presidente Émile Loubet

1902:

Septiembre: Muerte de Émile Zola, en circunstancias extrañas.

1903:

Abril: Reapertura del proceso Dreyfus en la Cámara legislativa por Jean Jaurès.

\section{6:}

Julio: El Tribunal Supremo anula el juicio de Rennes, determinando la amnistía para todos los acusados.

Rehabilitación de Dreyfus, ascenso a jefe de batallón y nombramiento como Caballero de la Legión de honor.

El teniente coronel Picquart, asciende a general de brigada y es nombrado ministro de Guerra, por Clemenceau.

Diciembre: Las cenizas de E. Zola son trasladadas al Panthéon.

1930:

Publicación de los cuadernos de agregado alemán en París, Max von Schwartzkoppen. Reconocimiento de la culpabilidad de Esterházy y de la inocencia de Dreyfus.

Confrontar a este respecto: www.cahiers-naturalistes.com/chronologie_dreyfus.htm.

${ }^{138}$ En un artículo titulado Une nouvelle affaire Dreyfus?, publicado por René Bernard en L'Express, del 9 al 15 de agosto de 1985, se evidencia la polémica suscitada ante el proyecto de elaboración de una estatua al capitán Alfred Dreyfus, al que el preseidente socialista François Mitterand quería rendir homenaje.

La estatua fue solicitada por el ministro de cultura Jacques Lang y propuesta al dibujante, pintor y escultor Louis Mitelberg, Tim. La estatua, realizada en bronce, representa al capitán Dreyfus de pie, con un sable roto en las manos, ante la cara, símbolo del ultraje que se le realizó al ser este sable roto ante las tropas.

Esta estatua se iba a situar en el patio de la Escuela Militar, porque fue el lugar donde Dreyfus fue degradado, pero al comprobar que no era un lugar muy visitado, se cambió su emplazamiento al patio de la Escuela Politécnica donde Dreyfus realizó sus estudios. Pero la polémica y las marcas antisemitas resurgen en la sociedad y la escultura permaneció terminada en el taller del escultor durante dos años, siendo colocada en las Tuileries e inaugurada por el ministro de cultura el 9 de junio de 1988. Dos días después Le Monde titula que el honor del oficial francés, injustamente condenado, se ha lavado con el bronce de la estatua.

Sin embargo, a pesar de todos estos honores oficiales, unos días después, el 20 de junio, la tumba del capitán Dreyfus, en el cementerio parisino de Montparnasse, aparecí́ profanada y la lápida con pintadas que representaban unas cruces gamadas y el epitafio: "traître et Jude".

${ }^{139}$ PAGÊS, Alain, 1998, op. cit. pág. 183.

${ }^{140}$ Allocution de M. Alain Richard, Ministre de la Défense, École militaire, 2 février 1998, in Cahiers Natutralistes, $n^{0} 72$, Besançon, 1998, pág. 33. 
BÄHLER, U.: Gaston Paris dreyfusard. Le savant danns la cité, CNRS Éditions, París, 1999.

BECKER, C. (éd.): La vérité en marche, Garnier-Flammarion, París, 1969.

BILLARD, T.: Félix Faure, Julliard, París, 1995.

BIRNBAUM, P.: L'Affaire Dreyfus, la République en péril, Gallimard, coll. Découvertes, París, 1997.

BOUSSEL, P.: L'Affaire Dreyfus et la presse, A. Colin, Paris, 1960.

BREDIN, J.D.: L'Affaire, Ed. Julliard, París, 1983, Fayard, París, 1993.

------ : Bernard Lazare, Ed. De Fallois, 1997.

CAHIERS NATURALISTES, n 72, Grasset-Fasquelle, Besançon. 1998.

CHENE, J.; ABERDAM, E. Et D. (ed.): Comment devient-on dreyfusard?, L'Harmattan, París/Montréal, 1997.

CLEMENCEAU, G.: L'affaire Dreyfus, L'Iniquité, introducción de Michel Drouin, Editions Mémoire du Livre, París, 2001.

DOISE, J.: Un secret bien gardé: Histoire militaire de l'affaire Dreyfus, Seuil, París, 1994.

DREYFUS, M.: L'Affaire, telle que je l'ai vécue, Grasset, París, 1978.

------ : Carnets, Calmann-Lévy, París, 1998.

GERVEREAU, L.; PROCHASSON, CH. (dir.): L'Affaire Dreyfus et le tournant du siècle(1894-1910), catalogue, París, BDIC, 1994.

GIRARD, P.: Pour le meilleur et pour le pire, Ed. Bibliophane, 1996.

GRAND-CARTERET, J.: L'affaire Dreyfus et l'image, Flammarion, Paris,1898.

GUIEU, J.-M. (ed.): Intolérence et indignation. L’Affaire Dreyfus, Ed. Fischbacher, 2000.

HALÉVY, D.: Regards sur l'affaire Dreyfus, Éd. de Fallois, 1994.

JAURÈS, J.: Les Temps de l'affaire Dreyfus, 1897-1899, tomo VI y VII de sus Oeuvres, edición de Eric Cahm y Madelaine Rébérioux, Fayard, París, 2001.

JEAN JAURÈS, cahiers trimestriels: J'Accuse et les Preuves, nº151, 2000.

KLEEBATT, N.: The Dreyfus Affair-truth and justice, 1987.

KOREN, R.; MICHMAN, D. (ed.): Les intellectuels face à l'Affaire Dreyfus alors et aujourd'hui. Perception et impact de l'Affaire en France et à l'étranger, L'Harmattan, París/Montréal, 1998.

LEYMARIE, M. (ed.): La postérité de l'Affaire Dreyfus(avec une préface d'Antoine Prost et une conclusion de Serge Berstein), Presses Universitaires du Septentrion, Villeneuved'Ascq, 1998.

LIPSCHUTZ, L.: "Une bibliothèque dreyfusienne. Bibliographie thématique et analytique de l'affaire Dreyfus", Cahiers Naturalistes, n³7, 1969, pp. 91-101.

MARRUS, M.: Les Juifs de France à l'époque de l'Affaire Dreyfus, Ed. Calman-Lévy, París, 1972.

MARTIN. M.: Medias et journalites de la République, Odile Jacob, París, 1997.

MIQUEL, P.: L'Affaire Dreyfus, PUF, Que sais-je, París, 1959.

------ : El Caso Dreyfus. Colección Popular. Fondo de Cultura Económica. México.

MITTERAND, H.: Émile Zola: carnets d'enquêtes. Une ethnographie inédite de la France, Plon, Coll. Terre humaine, París, 1987.

NIVET, Jean-François: "Octave Mirbeau entre espoirs et cauchemars", en Les Cahiers Naturalistes, Fasquelle, París, nº 61, págns 218-227. 
ORIOL, Ph. (ed.): Alfred Dreyfus, Carnets(1899-1907). Après le procès de Rennes, préface de Jean-Denis Bredin, Calman-Lévy, París, 1998.

PAGÈS, A. (ed.): Zola. L'Affaire Dreyfus. Lettres et entretiens inédits, CNSE Edit., París, 1994.

PAGÈS, A.: 13 janvier 1898, "J'Accuse...!", Perrin, coll. "Une journée dans 1'Histoire", París, 1998.

RACINE, N.: La postériorité de l'Affaire Dreyfus. Ed. Michel Lemayre, prefacio de Antoine Prost, conclusión de Serge Berstein, Presses Universitaires du Septeptrion, 1998.

ROYO HERNÁNDEZ, S.: Orígenes de la xenofobia en Europa: el affaire Dreyfus, www.lacavernade platon.com/articulosbis/dreyfus.htm.

SOBLIN, P.: La Croix et les Juifs, Grasset, París, 1967.

TUCHMAN, B.: L'Autre Avant-guerre, trad. de l'anglais par René Jouan, Plon, París, 1967.

RÉBÉRIOUX, M.: Jaurès. La parole et l'acte, Gallimard, París, 1997.

WEILL, N.: Meurtre à l'Aurore, Ed. Calman-Lévy, París, 1994.

WILSON, N.: Bernard-Lazare, A. Michel, París, 1985.

WINOCK, M.: Nationalisme, antisémitisme et fascisme en France, Seuil, Points Histoire, París, 1990.

: L'Affaire Dreyfus. Vérités et mensonges, Seuil, coll. Points, París, 1998.

WHYTE, G.R.: The accused. The Dreyfus Trilogy, Coda Editions, Londres/ Inter Nationes, Bonn, 1996.

ZIEGER, K. (ed.): "Émile Zola, J'accuse. Réactions nationales et internationales", in Recherches valenciennoises, $n^{\circ} 2$, Presses de l'Université de Valenciennes, $n^{\circ} 151,2000$. ZOLA, É.: La vérité en marche, Gallimard, coll. Découvertes, Paris, 1997.

: J'accuse, postfase de Michel Polac, ed. Mille et une nuits, janvier, 1994.

: Yo acuso. La verdad en marcha, traducción Prensa Ibérica, Barcelona, 1998. 
